\title{
Structural, Electrical and Ferroelectric Properties of Lead-free Bi(Fe0.85dy0.15)o3 Electroceramic Compound
}

\section{Thansanga}

NIT Mizoram: National Institute of Technology Mizoram

Dr Alok Shukla ( $\square$ aloks.nitmz@gmail.com )

National Institute of Technology Mizoram https://orcid.org/0000-0003-2033-8415

Nitin Kumar

NIT Mizoram: National Institute of Technology Mizoram

R.N.P. Choudhary

SOA University: Siksha O Anusandhan University

\section{Original Research}

Keywords: X-ray diffraction, Dielectric, Impedance, Conductivity, Ferroelectric

Posted Date: February 8th, 2021

DOl: https://doi.org/10.21203/rs.3.rs-170994/v1

License: (c) This work is licensed under a Creative Commons Attribution 4.0 International License.

Read Full License

Version of Record: A version of this preprint was published at Journal of Materials Science: Materials in Electronics on July 22nd, 2021. See the published version at https://doi.org/10.1007/s10854-021-066365 . 


\title{
Structural, Electrical and Ferroelectric Properties of Lead-Free $\mathrm{Bi}\left(\mathrm{Fe}_{0.85} \mathrm{Dy}_{0.15}\right) \mathrm{O}_{3}$ Electroceramic Compound
}

\author{
L. Thansanga ${ }^{1}$, Alok Shukla ${ }^{1} *$, Nitin Kumar ${ }^{1}$, R.N.P. Choudhary ${ }^{2}$ \\ ${ }^{1}$ Department of Physics, National Institute of Technology Mizoram, Aizawl-796012, India \\ ${ }^{2}$ Multifunctional Materials Research Laboratory, Department of Physics, ITER, SOA \\ (Deemed to be University), Bhubaneswar-751030, India
}

\begin{abstract}
This paper mainly reports detailed studies of structural, dielectric, impedance and ferroelectric properties of $\mathrm{Bi}\left(\mathrm{Fe}_{0.85} \mathrm{Dy}_{0.15}\right) \mathrm{O}_{3}$ (termed as $\mathrm{BFDO15)}$, fabricated via solid state reaction (SSR) method. Analysis of X-ray diffraction (XRD) data confirm the crystal symmetry changes from rhombohedral to orthorhombic symmetry. The scanning electron micrograph collected through field emission scanning electron microscopy (FE-SEM) shows a regular distribution of grains over the sample surface. The elemental composition of the sample was examined by using energy dispersive X-ray micro-analysis (EDXMA) and this confirms the existence of constituent elements of the sample. The electrical measurement was carried out using a computer-controlled phase sensitive multimeter (PSM) in a frequency range of $1 \mathrm{kHz}-1000$ $\mathrm{kHz}$ and temperature range of $25^{\circ} \mathrm{C}-500{ }^{\circ} \mathrm{C}$. Study of dielectric properties shows high dielectric permittivity and small value of dielectric loss in the sample. The frequency dependent impedance and electrical modulus analysis reveals the presence of a semiconducting nature and non-Debye type relaxation process. Analysis of ac-conductivity with respect to frequency obeys the universal Jonscher's power law. The electric polarization study shows enhancement in ferroelectric property of the material. Hence, based on the significant enhancement found in the structural, electrical and ferroelectric properties of BFDO15 material, it could be a promising candidate for modern device applications.
\end{abstract}

Keywords: X-ray diffraction; Dielectric; Impedance; Conductivity; Ferroelectric.

*Corresponding author:

E-mail:- aloks.nitmz@gmail.com (Dr. Alok Shukla) 


\section{Introduction}

A tremendous research interest in multiferroic materials, which are having simultaneously both the ferroelectricity as well as ferromagnetic order in a single phase at higher temperatures, have been experienced since the past few decades. Development of lead-free multiferroic materials added some advantages in our environment concerned and health issues of human beings as they are considered as toxic free materials for electronic device applications including information storage media, actuators, spintronics, transducers, sensors and optoelectronic devices [1-3]. Despite the tenacious efforts had been paid for the development of novel single phase multiferroics, bismuth ferrite (BFO) is perhaps the most aware material which have both magnetic and a strong ferroelectric (multiferroic) behavior at/above room temperature. Bismuth ferrite possesses an $\mathrm{ABO}_{3}$ type distorted perovskite rhombohedral symmetry with a space group of $R 3 \mathrm{c}$ below the ferroelectric Curie temperature $\left(T_{c}=830^{\circ} \mathrm{C}\right)$, which have the unit cell value of $a=b=5.558 \AA$ and $c=13.87 \AA$ and its rhombohedral angle is $89.3^{\circ}-89.48^{\circ}$ $[4,5]$. BFO becomes antiferromagnetic with $G$-type structure below its magnetic Neel temperature $\left(T_{N}=620^{\circ} \mathrm{C}\right)$. The main reason of the ferroelectricity of BFO is originated from $6 s$ lone pair electrons of $\mathrm{Bi}^{3+}$ ions while the ferromagnetic/antiferromagnetic property was attributed to partly filled $d$ orbital of $\mathrm{Fe}^{3+}$ ions [6]. Despite being multiferroicity at/above room temperature, BFO possesses some inherent drawbacks such as structural distortion, high current leakage density, high coercive field, low remnant polarization due to irregular magnetic spin structure which hindered its potential device applications [7,8]. However, researchers had identified the ways to strengthening and improving the multiferroic properties of BFO by substituting other certain components at $\mathrm{AB}$ or $\mathrm{A} / \mathrm{B}$ site. It has learned from the literature review that doping at the A-site using alkaline earth ions is an effective way for enhancing the multiferroic property of BFO [9-12]. Several groups of researchers had attempted through SSR method, sol-gel technique and solution combustion method at A-site substitution using some rare earth ions including $\mathrm{Dy}^{3+}, \mathrm{Gd}^{3+}, \mathrm{Sm}^{3+}, \mathrm{La}^{3+}$ and found that enhancement in magnetic properties as well as electrical features of bismuth ferrite [13-16]. Some investigations reported that substitution by several divalent ions such as $\mathrm{Ca}^{2+}$ [17], $\mathrm{Mn}^{2+}[18], \mathrm{Ba}^{2+}[19]$ and $\mathrm{Sr}^{2+}, \mathrm{Pb}^{2+}$ [20] at both sites (AB-site) of BFO had also improved the structural and ferroelectric properties of BFO.

Based on the literature survey, most of the Dy doped BFO reported are at A-site doping or co-doping with some other elements while B-site Dy substitution has not yet been widely explored. In this work, we mainly focussed on the impact of B-site Dy substitution on structural, dielectric, electrical (i.e. impedance, modulus, conductivity) and ferroelectric 
features of $\mathrm{BFO}$ having a composition of $\mathrm{Bi}\left(\mathrm{Fe}_{0.85} \mathrm{Dy}_{0.15}\right) \mathrm{O}_{3}$, which was synthesized through a high-temperature (calcination at $750{ }^{\circ} \mathrm{C}$ for $8 \mathrm{~h}$, sintering at $800{ }^{\circ} \mathrm{C}$ for $6 \mathrm{~h}$ ) cost effective solid state reaction method. All the analyses were carried out within a frequency range of $1 \mathrm{kHz}-$ $1000 \mathrm{kHz}$ and temperature range of $25^{\circ} \mathrm{C}-350{ }^{\circ} \mathrm{C}$. The enhancement in physical as well as electrical properties by virtue of Dy-doping $(x=0.15)$ at B-site of bismuth ferrite has been reported in this work.

\section{Experimental method}

\subsection{Synthesis of sample}

A polycrystalline sample, $\mathrm{Bi}\left(\mathrm{Fe}_{0.85} \mathrm{Dy}_{0.15}\right) \mathrm{O}_{3}$ was synthesized using an analytical grade oxides and carbonates such as $\mathrm{Bi}_{2} \mathrm{O}_{3}$ (99\% purity, M/s Himedia product), M/s Loba Chemie Co. Ltd. product $\mathrm{Fe}_{2} \mathrm{O}_{3}\left(98 \%\right.$ purity) and $\mathrm{Dy}_{2} \mathrm{O}_{3}(99 \%$ purity) via a solid state reaction method. A Mettler Toledo digital balance (ML204/A01) was used for weighing the primary ingredients. All the ingredients were mixed homogeneously using mortar and pestle in a dry medium (air) for $3 \mathrm{~h}$ and wet (methanol) medium for $3 \mathrm{~h}$ in order to obtain a regular mixture sample. The mixed powder has been heated at an optimized temperature and time $\left(750{ }^{\circ} \mathrm{C}\right.$ for $\left.8 \mathrm{~h}\right)$. In order to make a sample pellet, $2 \%$ of polyvinyl alcohol (binder) was added to the heated powder. The cylindrical shaped pellets having a diameter of $11.75 \mathrm{~mm}$ and thickness $1.8 \mathrm{~mm}$ were made by applying iso-static pressure of $5 \times 10^{4} \mathrm{Nm}^{-2}$. Sintering process of the sample pellets was carried out at an optimized temperature $800{ }^{\circ} \mathrm{C}$ in an electric furnace for $6 \mathrm{~h}$. The high quality alumina crucibles of a cylindrical, boat and tray were utilized during the calcination and sintering process of the material.

\subsection{Characterization of material}

The basic crystal structure and phase formation of BFDO15 was measured by XRD (D8 Advance, Bruker) by applying $\mathrm{CuK \alpha}(\lambda=1.5405 \AA)$ radiation at $2^{\circ} / \mathrm{min}$ scan speed over Bragg's angle $\theta\left(20^{\circ} \leq 2 \theta \leq 80^{\circ}\right)$. POWDMULT software was utilized for measuring the unit cell parameters, the crystal system and Miller indices of BFDO15. The sample surface morphology has been measured using the FE-SEM (Carl Zeiss) for studying the distribution of grains, grain size, microstructure and density of grains. The elemental study of a sample was carried out by using energy dispersive X-ray spectroscopy (EDXS). The cylindrical shaped pellets were flattened with the help of a fine emery paper in order to get parallel and smooth surface of pellet, and then coated with a high quality silver paste (Alfa Aesar) and dried at $150{ }^{\circ} \mathrm{C}$ for $1 \mathrm{~h}$ in order to eliminate the moisture. The dielectric constant, tangent loss and other electrical parameters were measured using a high precision computer-interfaced PSM (N4L, 1735) over 
a frequency range of $1 \mathrm{kHz}-1000 \mathrm{kHz}$ and temperature $\left(25^{\circ} \mathrm{C}-500{ }^{\circ} \mathrm{C}\right)$. A room temperature electric field polarization of the sample was measured using $P-E$ loop tracer (Marine, India).

\section{Results and discussion}

\subsection{Structural study}

Fig. 1 represents room temperature XRD pattern of sintered $\mathrm{Bi}\left(\mathrm{Fe}_{0.85} \mathrm{Dy}_{0.15}\right) \mathrm{O}_{3}$ material. The sharp and narrow X-ray diffraction peaks indicate the proper crystalline nature as well as the development of a pure phase material. However, few peaks which have a very small intensities corresponds to the $\mathrm{Bi}_{25} \mathrm{FeO}_{40}$ and $\mathrm{Bi}_{2} \mathrm{Fe}_{4} \mathrm{O}_{9}$ crystal system [21] (shown as * symbol in the figure) and such a small impurity is a common problem in bismuth-based materials [22]. Measurement of the unit cell dimension was carried out using X-ray data refinement and indexing software known as "POWDMULT" [23]. The unit cell dimensions and crystal system of the sample were estimated according to the best agreement between (a) the observed and measured inter-planar spacing $(d)$ and (b) diffraction angles. Based on this evaluation, the change of rhombohedral crystal system to orthorhombic symmetry has been confirmed. The value of refined lattice factors are $a=4.0103 \AA, b=15.8409 \AA, c=29.3948 \AA$ and Volume, $V$ $=1867.36 \AA^{3}$ with a minimum standard deviation, $S D=0.019$. A good agreement in a diffraction peak of each reflections suggests the validity of a crystal system and unit cell parameters. The observed $\left(d_{o b s}\right)$ and calculated $\left(d_{c a l}\right)$ interplanar spacing and the value of their Miller indices $(h k l)$ were represented in Table 1. Sizes of each sample particles $(P)$ were estimated by Scherrer's formula [24]:

$P=k \lambda / \beta_{1 / 2} \cos \theta$

where $\lambda=0.15407 \mathrm{~nm}, k$ is constant $=0.89, \theta$ is maximum peak position and $\beta_{1 / 2}$ is peak width at half maximum. The approximate crystallite size of BFDO15 is $38 \mathrm{~nm}$.

\subsection{Microstructural analysis}

Fig. 2a displays the FE-SEM micrograph of BFDO15, which shows the different size of grains having a rectangular shape. The surface morphology of the sample clearly illustrates uniform distribution of grains in an agglomerated nature with a small void and densely packed without cracking surface. Variation of size and shape of grains with their respective boundaries are also easily distinguishable from the FE-SEM micrograph. Several sizes of grains are measured with the help of a standard software called "ImageJ" and approximated to be $1.039 \mu \mathrm{m}$. The microstructural study was carried out using the EDXS as shown in Fig. 2b. This analysis confirmed the presence of bismuth, iron, dysprosium and oxygen (its constituent elements) 
with their respective atomic ratios and the purity of the sample. Moreover, EDXS analysis also reveals that BFDO15 material was effectively synthesized without impurities. The weight and atomic percentage of the constituent elements of the sample are tabulated in Table 2.

\subsection{Dielectric study}

\subsubsection{Temperature dependent dielectric property}

Study of dielectric properties of a compound is one of the most important features in advanced ceramic materials as it offers an information about the dielectric permittivity and dielectric loss of the studied material under the specified orientation of applied electric field and frequency. The dielectric parameters of a material are usually depending on various factors including elemental composition, pressure, temperature, size of particles, applied frequency and electric field, etc. The electrical parameters such as impedance factor (Z), dielectric constant $\left(\varepsilon_{\mathrm{r}}\right)$, dielectric loss $(\tan \delta)$, phase angle $(\theta)$, material dissipation factor (D) and capacitance $\left(\mathrm{C}_{\|}\right)$were recorded with the help of high accuracy phase sensitive multimeter connected with a computer-controlled temperature furnace. Therefore, in order to know the potential applications and better understanding, it is an essential to study the dielectric properties of the sample. Dielectric constant of the sample is calculated by using the general capacitance formula given below:

$$
\varepsilon_{r}=C_{p} \frac{t}{\varepsilon_{0} A}
$$

herein, $C_{p}=$ capacitance in parallel mode, $t=$ thickness of the sample pellet, $A=$ area of the sample pellet and $\varepsilon_{0}=$ permittivity of free space.

Fig. 3a displays the change of dielectric constant $\left(\varepsilon_{r}\right)$ versus temperature $\left(25{ }^{\circ} \mathrm{C}-350{ }^{\circ} \mathrm{C}\right)$ for a sintered BFDO15 material. Initially, a temperature independent nature of dielectric permittivity has been detected at low temperature range, however, $\varepsilon_{r}$ slowly increases with an increasing temperature for all the operating frequencies and the first hump was observed at 164 ${ }^{\circ} \mathrm{C}$, which may be originated due to the magnetic transition in the as-prepared material [25]. Generally, due to the existence of different types of polarization (i.e. ionic, atomic, orientation, space charge) at low frequency region, higher value of $\varepsilon_{r}$ was found at low frequency curves $(1-50 \mathrm{kHz})$ as shown in the figure [26]. Such polarizations slowly vanish with an increasing frequency and as a result, the dielectric permittivity decreases. The value of $\varepsilon_{r}$ gradually increases as the temperature rises and the second dielectric peak occurs at $334{ }^{\circ} \mathrm{C}$, which probably ascribed to the ferromagnetic-antiferromagnetic phase transition in the present studied sample. In addition, the two dielectric peaks observed from the plot recommends the 
existence of multiple phase transition in the sample. From Fig. 3a, the value of dielectric constant at $1 \mathrm{kHz}$ for temperatures $25^{\circ} \mathrm{C}$ and $350{ }^{\circ} \mathrm{C}$ are 4,133 and 41,410 respectively. In addition, the value of $\varepsilon_{r}$ at $1 \mathrm{MHz}$ at temperatures $25^{\circ} \mathrm{C}$ and $350{ }^{\circ} \mathrm{C}$ are 751 and 1,536 , respectively.

Fig. $3 \mathrm{~b}$ shows the dielectric loss characteristics of BFDO15 material with temperature at a set of frequencies $(1 \mathrm{kHz}-1 \mathrm{MHz})$. The dielectric loss $(\tan \delta)$ seems constant at low and intermediate temperature region. In other words, the temperature independent behavior of $\tan \delta$ has been observed irrespective of the frequencies up to $200^{\circ} \mathrm{C}$. Nevertheless, the dielectric loss rises exponentially with an increasing temperature beyond $250{ }^{\circ} \mathrm{C}$ and two peaks were found at $295{ }^{\circ} \mathrm{C}$ and $339{ }^{\circ} \mathrm{C}$, which were attributed to the random dispersion of thermally influenced charged carriers and oxygen vacancies developed during the high temperature sintering process of the sample [27]. In spite of these defects, decreases of dielectric loss was observed in this sample. The $\tan \delta$ plot clearly illustrates higher value of loss factor is detected at lower frequency curves which mainly arise due to the effect of existence of iron $(\mathrm{Fe})$ in the asprepared material. The calculated value of dielectric loss of the material at room temperature $\left(25^{\circ} \mathrm{C}\right.$ ) for a frequency of $1 \mathrm{kHz}$ and $1 \mathrm{MHz}$ are found to be 0.5922 and 0.5606 respectively, while a minor increase of loss factor was found at $350{ }^{\circ} \mathrm{C}(1 \mathrm{kHz}$ and $1 \mathrm{MHz})$ with a loss value, 14.895 and 2.4861 respectively. The comparison of temperature dependent dielectric constant $\left(\varepsilon_{\mathrm{r}}\right)$ and dielectric loss $(\tan \delta)$ of sintered $\mathrm{Bi}\left(\mathrm{Fe}_{0.85} \mathrm{Dy}_{0.15}\right) \mathrm{O}_{5}$ compound at selected temperatures and frequencies are summarized in Table 3.

\subsubsection{Frequency dependent dielectric property}

Fig. 4a illustrates the characteristics of a dielectric constant $\left(\varepsilon_{r}\right)$ as a function of frequency at some set of temperatures $\left(25^{\circ} \mathrm{C}-350^{\circ} \mathrm{C}\right)$ for BFDO15 compound. The plot shows that the value of dielectric constant rapidly decreases as the frequency increase and then combines at higher frequency region. The decreasing trend of dielectric constant strongly recommends the polar nature of the present studied compound. At lower frequency region, a high value of dielectric permittivity is observed due to the presence of different types of polarizations (atomic, ionic, dipolar, electronic, interfacial polarization) and charge accumulation at the grain boundary interfaces whereas electronic polarization dominates higher frequency region and then results small value of dielectric permittivity [28]. Moreover, most of the dipoles are not strong enough to follow the increasing frequency at higher frequency region which results decrease of dielectric permittivity at higher frequency region. Therefore, a significant contribution only from electronic polarization is received at higher frequency among the 
different types of polarizations, which subsequently results small value of dielectric constant [29]. The dispersive spectrums found at lower frequency region suggests the effect of grain boundary which spreads throughout the sample surface [30].

The graphical representation of dielectric $\operatorname{loss}(\tan \delta)$ as function of frequency is shown in Fig. 4b. The nature of the plot may be explained by a two-layer model which was proposed based on Koop's theory by Maxwell and Wagner [31]. This theory states that at low frequency, electrons are very effective as compared with other factors whereas grains are more active as compared with electrons at high frequencies. Due to the high resistive nature at grain boundary, more energy is required for moving charge carriers at low frequency region, which subsequently results high value of dielectric loss. On the other hand, a small amount of energy is used for moving charge carriers at higher frequency region due to the high conductivity and then consequences small value of dielectric loss at higher frequencies.

\subsection{Electrical impedance spectroscopy}

\subsubsection{Real (Z') and imaginary (Z') component of impedance study}

Electrical impedance spectroscopy is one of the most powerful technique for investigating the dielectric and electrical characteristics of advanced ceramic materials. It has been commonly used for studying the grain and grain boundary effects and interface effect in a polycrystalline dielectric and ionic conductors [32,33]. The nature of electrical response as well as characteristics of real and imaginary components of the sample also can be examined using the experimental data. In addition, this technique is utilized for examining dynamics of the movement of ions in solid materials. Generally, an ac-signal is applied to silver coated pellet sample in order to measure the electrical response of the sample specimen, then analyzed and presented in different formats for studying its electrical properties. The real (Z') and imaginary (Z') part of impedance of a complex impedance $\left(Z^{*}=Z^{\prime}-i Z^{\prime \prime}\right)$ can be determined by using the given formula [29]:

$$
\begin{aligned}
& Z^{\prime}=\frac{R}{1+(\omega \tau)^{2}} \\
& Z^{\prime \prime}=\frac{R \omega \tau}{1+(\omega \tau)^{2}}
\end{aligned}
$$

herein, $\tau=\mathrm{RC}=$ relaxation time, $\omega=$ angular frequency. 
Fig. 5a illustrates the characteristics of real component of impedance $\left(Z^{\prime}\right)$ versus frequency for BFDO15 material. The value of $Z$ ' sharply falls with an increasing frequency at lower frequency region (1-40 kHz). Then, the impedance spectrums amalgamate regardless to temperature at higher frequency division $(40-1000 \mathrm{kHz})$, which was associated to the release of space charge and electrode effect [34]. The presence of decrement in barrier features with increasing temperature may also be associated with the increase of conductivity at higher frequencies [35]. The dispersive spectrum at low frequency division has also been noticed from the plot, that shows the decreasing nature of $Z$ ' with an increasing temperature suggesting the negative temperature coefficient of resistance (NTCR) behavior of the as-prepared material, it is the common feature of a semiconducting materials. The decreasing trend of $Z$ ' with a growing temperature as well as frequency is good in line with our other impedance result [29].

Fig. 5b depicts the characteristics of an imaginary part of impedance ( $Z$ ') versus frequency at some specific temperatures $\left(25-350{ }^{\circ} \mathrm{C}\right)$ for BFDO15 material. The figure clearly displays numerous features such as merger of spectrum at higher frequency, irregular peak broadening with the increase of temperature, difference of peak trend with an increasing temperature. The $Z$ ' spectrum displays the decreasing trend with the rise of frequency and combines at higher frequency site. The broadening of peaks gradually decreases with a growing temperature recommends the existence of temperature influenced electrical relaxation process in the sample. Moreover, it also suggests the presence of several types of electrical relaxation process/strength exists in a specific frequency [36]. The electrical relaxation processes of the sample are generally originated due to existence of immobile charge carriers (electron) at lower temperature and vacancies/defects created at higher temperature [37]. We can imagine the spread of relaxation time from the width of peaks as shown in Fig. 4b.

\subsubsection{Nyquist plot}

Fig. 5c illustrates Nyquist plot ( $Z$ ' vs $Z$ '’) of BFDO15 at a set of temperatures. The plot shows a different semi-circular arc which are slowly depressed with an increasing temperature towards $Z$ ' axis. The electrical relaxation contributed by grain and grain boundary can be distinguishable from the interception of semi-circular arcs with the real axis (i.e. $x$-axis). According to the ideal Debye type relaxation, the centre of a semicircles should lie on/above the real axis. Nevertheless, it is obvious from the plot that the centre of a semi-circular arcs were falls below the real axis ( $x$-axis), which confirms the presence of non-Debye type of electrical relaxation process in BFDO15 material [38]. Moreover, the graph clearly shows that the grain and grain boundary contribution of relaxation process at lower temperature $\left(<250{ }^{\circ} \mathrm{C}\right)$ 
and higher temperature $\left(>275^{\circ} \mathrm{C}\right)$ spectrums, respectively. The behavior of semi-circular arcs reveals the existence of distribution of relaxation time which were originated by irregular distribution of grains in our sample [39].

\subsection{Electrical modulus spectroscopy}

The electrical modulus spectroscopy is one of the most useful technique for examining the nature of electrode polarization, electrical conductivity, conduction mechanism, relaxation time and the effect of bulk and grain boundary properties of the as-prepared material [40]. In addition, this method can also be utilized for studying several types of electrical processes which developed in the present studied compound. The real $\left(M^{\prime}\right)$ and imaginary part $\left(M^{\prime}\right)$ of modulus can be determined by using the mathematical relation [41] given below:

$$
\begin{aligned}
& M^{\prime}=A\left[\frac{(\omega R C)^{2}}{1+(\omega R C)^{2}}\right]=A\left[\frac{\omega^{2} \tau^{2}}{1+\omega^{2} \tau^{2}}\right] \\
& M^{\prime \prime}=A\left[\frac{\omega R C}{1+(\omega R C)^{2}}\right]=A\left[\frac{\omega \tau}{1+\omega^{2} \tau^{2}}\right]
\end{aligned}
$$

herein, $A=\frac{C_{0}}{C}$, all the symbols have their usual meanings.

Fig. 6a displays the change of real modulus component $\left(M^{\prime}\right)$ versus frequency at a set of temperatures for BFDO15 compound. The value of $M^{\prime}$ is nearly zero at low frequency due to the electrode polarization contribution and the accumulation of space charge at the grain boundary interface. A continuous dispersive nature of $M^{\prime}$ spectrum with an increasing frequency is observed, while $M^{\prime}$ value falls with an increasing temperature and shows a highly dispersive nature at higher frequency side due to the short range mobility of charge carriers/ions that spread over a wide range of frequency. The trend behavior of $M$ ' spectrum suggests that grains are accountable for the electrical properties of the sample. The culminate point for all the operating temperatures $\left(25-350{ }^{\circ} \mathrm{C}\right)$ has been observed at high frequency region which indicates the existence of electrode polarization phenomena in the sample $[42,43]$.

Fig. $6 \mathrm{~b}$ illustrates the division of imaginary modulus component $\left(M^{\prime}\right.$ ') versus frequency at some selected temperatures for BFDO15 compound. The magnitude of $M$ '" is found to be nearly zero at low frequency and rises gradually as the frequency increases. The relaxation peak of $M$ '" shifted towards higher frequency region when the temperature increases and faster movement of charge carriers was observed and these results decreases in a relaxation time [44,45]. The trend behavior of $M$ ' ' clearly indicates the existence of temperature dependent relaxation process and hopping charge mechanism in the material $[46,47]$. Moreover, the continuous increasing curve of the $M$ ', spectrum for all the selected temperatures signifies that 
the ions can successfully jump from one site to the neighbouring site [48]. In addition, the asymmetric broadening of peaks/curves found in the plot recommends non-Debye type of relaxation process in the material.

\subsection{Electrical conductivity study}

Electrical conductivity analysis of a compound is an important method for determining electrical conduction mechanism which is required for examining transport properties of material. Conduction mechanism of materials is mainly influenced by microstructure of the sample and defects. In perovskite materials, the synthesis process such as calcination and sintering temperature, atmosphere, time, etc. can generate oxygen as well as cation vacancies and other defects [49].

Fig. 7a shows the change of ac-conductivity versus frequency at some temperature sets for $\mathrm{Bi}\left(\mathrm{Fe}_{0.85} \mathrm{Dy}_{0.15}\right) \mathrm{O}_{3}$ material. It is noted that the value of ac-conductivity $\left(\sigma_{a c}\right)$ linearly increases as the frequency increase and tends to merge all the spectra at high frequency site. The frequency dependent electrical conductivity may be divided into two regions: (a) A plateau found at low frequency region and (b) a dispersion at high frequency region. At lower frequency, ac-conductivity seems not depends on frequency by forming a plateau. This frequency independent region is considered as zero-frequency conductivity $\left(\sigma_{o}\right.$ or $\left.\sigma_{d c}\right)$, which occurs due to thermally influenced space charge carriers. On the other hand, the frequency dependent conductivity was found at higher frequency region, so this site is considered as acconductivity $\left(\sigma_{a c}\right)$. Therefore, the $\sigma_{a c}$ may be calculated from the dispersive region (higher frequency site) using Jonscher's power law: $\sigma(\omega)=\sigma(d c)+A \omega^{n}$, where $\sigma(\omega)$ is the total conductivity, $\sigma(d c)$ is the direct current conductivity of a sample, $A$ is constant depending on temperature and $n$ is the temperature dependent exponential. According to this, when a mobile charge carrier hops from one site to its neighbouring site, it persists in an oscillation state between two possible minimum energy [50]. Generally, at low frequency, the ions jump from their original site to the neighbouring vacant sites, whereas at higher frequencies, some ions move back to their original site through hopping process, which may results increase in conductivity at low frequencies [51]. The exponent $n$ is related to the hopping rate and relaxation time. The hopping process becomes slower as compared with site relaxation, if $n<$ 1 , whereas if $n>1$, back-hopping conduction process is faster as compared with site relaxation [52]. 
Fig. 7b shows the temperature dependent ac-conductivity $\left(\sigma_{a c}\right)$ characteristics of BFDO15 compound at some set of temperatures in an extensive range of frequency $(1 \mathrm{kHz}-1 \mathrm{MHz})$. The plot clearly shows that $\sigma_{a c}$ slowly increases as the temperature increase upto certain temperature and then suddenly falls at high temperature. However, it sharply increases as the temperature rises at further higher temperature region. The behavior of $\sigma_{a c}$ trend follows Arrhenius conductivity relation: $\sigma_{a c}=\sigma_{0} \exp \left(-E_{a} / k T\right)$, where symbols have their usual meanings. In addition, the continuous increases of $\sigma_{a c}$ with an increasing temperature confirmed the NTCR behavior of a sample. It has been observed that all the different frequency spectrum were merged at high temperatures which attributed to the recombination of released space charge at higher temperature [53]. Since, the hopping of electron and polaron plays an important role in a conduction mechanism, the value of activation energy, $E_{a}$ is high at lower frequency. It is also noticed from the plot that the activation energy rapidly increases with an increasing temperature while it decreases with an increasing frequency. As shown in Fig. 7b, the calculated $E_{a}$ of BFDO15 at $1 \mathrm{kHz}$ at an intermediate temperature (section - I) and higher temperature (section - II) is 0.24 and 3.29, respectively and value of $E_{a}$ at the two temperature regions at $1 \mathrm{MHz}$ is 0.18 and 2.38, respectively. The activation energy ( $\left.\mathrm{E}_{\mathrm{a}}\right)$ of $\mathrm{Bi}\left(\mathrm{Fe}_{0.85} \mathrm{Dy}_{0.15}\right) \mathrm{O}_{3}$ material calculated from the slope using Arrhenius relation at different temperature regions are shown in Table 4.

\subsection{Ferroelectric study}

Fig. 8 displays the polarization versus electric field $(P-E)$ loop of BFDO15 compound at room temperature. Measurement of ferroelectric loop was carried out by applying a frequency of 50 $\mathrm{Hz}$ and a potential of $25 \mathrm{kV} / \mathrm{cm}$. From the figure, it is noticed that unsaturated loop was observed due to the experimental limitations. Moreover, since the sample is composed of oxides, density of the sample and oxygen vacancy, which developed during the high temperature sintering process may influenced the current leakage behavior and which subsequently results lossy ferroelectric loop. The value of remnant polarization $\left(\mathrm{P}_{\mathrm{r}}\right)$ and coercive field $\left(E_{c}\right)$ in this unsaturated loop is $0.225 \mu \mathrm{C} / \mathrm{cm}^{2}$ and $18.70 \mathrm{kV} / \mathrm{cm}$, respectively. The movement of oxygen vacancy from one region to another in the applied field direction increases the mobility of charge carriers, so they tried to accumulate at the domain walls and electrode interface (low energy region). The electrical resistance of a material is mainly affected by the irregular distribution of oxygen vacancy and defects in composition of oxides. Therefore, the density and distributing nature of oxygen vacancy effects the width and height of Schottky barrier and then influenced the resistance of a material which subsequently affected 
the polarization switching behavior of the sample [54]. Finally, instead of being observed an unsaturated loop, a significant enhancement in the value of remnant polarization has been observed in the present studied sample as compared with pure BFO [55].

\section{Conclusion}

The electro-ceramic material, $\mathrm{Bi}\left(\mathrm{Fe}_{0.90} \mathrm{Dy}_{0.10}\right) \mathrm{O}_{3}$ was fruitfully synthesized via a conventional SSR route. The crystal structure was studied using powder XRD method and found that the structure changes from rhombohedral to orthorhombic symmetry and the average crystallite size is $38 \mathrm{~nm}$ (approximately). FESEM micrograph shows a regular distribution of grains and highly compact nature and the approximate grain size is $1.039 \mu \mathrm{m}$. The dielectric study shows that high dielectric constant value with a small and decreasing nature of dielectric loss with an increasing frequency due to the presence of electronic and interfacial polarization in the material. Impedance spectroscopy reveals the decreasing nature of $Z$ ' and $Z$ '" with the increase of frequency as well as temperature. The Nyquist plot confirms the presence of non-Debye type of electrical relaxation process in BFDO15 compound. Modulus spectroscopy ( $M^{\prime}$ and $M^{\prime \prime}$ ) analysis shows the presence of thermally motivated relaxation process in the sample. Acconductivity analysis shows the NTCR behavior and an increasing nature of conductivity with the increase of frequency while the activation energy rises as the temperature increases. $P-E$ loop analysis shows a significant improvement in remnant polarization. Hence, based on the several remarkable enhancements observed in the physical as well as electrical and ferroelectric properties, BFDO15 compound may be consider as a promising candidate for developing novel electronic applications.

\section{Acknowledgement}

The author, Dr Alok Shukla thankfully acknowledges SERB-DST, Govt. of India, for supporting this work in the form of Research Project (No. EMR/2015/002420).

\section{Conflict of interest}

The authors declared no conflict of interest in this work. 


\section{References}

[1] T. Varga, A. Kumar, E. lahos, S. Denev, M. Park, S. Hong, T. Sanehira, Y. Wang, C.J. Fennie, S.K Streiffer, X. Ke, P. Schiffer, V. Gopalan, J.F. Mitchell, Phys. Rev. Lett. 103, 047601 (2009)

[2] A. A. Belik, T. Furubayashi, Y. Matsushita, M. Tanaka, S. Hishita, E. TakayamaMuromachi, Chem. Int. Ed. 48, 6117 (2009)

[3] G. Catalan, J.F. Scott, Adv. Mater. 21, 2463 (2009)

[4] W. Eerenstein, N.D. Mathur, J.F. Scott, Nature 442, 759 (2006)

[5] Z.J. Li, Z.L. Hou, W.L. Song, X.D. Liu, W.Q. Cao, X.H. Shao, M.S. Cao, Nanoscale 8, 10415 (2016)

[6] C.W. Nan, M.I. Bichurin, S. Dongb, D. Viehland, J. Appl. Phys. 103, 031101 (2008)

[8] A. Ravalia, M. Vagadia, P. Trivedi, P.S. Solanki, K. Asokan, S. Ojha, O.P. Thakur, R.J. Choudhary, D.M. Phase, D.G. Kuberkar, Solid State Commun. 169, 10 (2013)

[9] M. Li, M. Ning, Y. Ma, Q. Wu, C.K. Ong, J. Phys. D: Appl. Phys. 40, 1603 (2007)

[10] V.A. Khomchenko, D.A. Kiselev, J.M. Vieira, L. Jian, A.L. Kholkin, A.M.L. Lopes, Y.G. Pogorelov, J.P. Araujo, Maglione, J. Appl. Phys. 103, 024105 (2008)

[11] G. Catalan, K. Sardar, N.S. Church, J.F. Scott, R.J. Harrison, S.A.T. Redfern, Phys. Rev. B 79, 212415 (2009).

[12] B. Bhushan, A. Basumallick, N.Y. Vasanthacharya, S. Kumar, D. Das, Solid State Sci. 12, 1063 (2010)

[13] S.K. Barbar, S. Jangid, M. Roy, F.C. Chou, Ceram. Int. 39, 5359 (2013).

[14] G.S. Lotey, N.K. Verma, J. Nanopart. Res. 14, 742 (2012).

[15] D. Maurya, H. Thota, A. Garg, B. Pandey, H.C. Verma, J. Phys.: Condens. Matter. 21, 026007 (2009).

[16] K. Sen, K. Singh, A. Gautam, M. Singh, Ceram. Int. 38, 243 (2012).

[17] V. Kumar, S. Singh, Appl. Surf. Sci. 386, 78 (2016).

[18] J.Y. Chen, W. Yao, D. Yuan, J. Appl. Phys. 116, 174102 (2014).

[19] M.R. Islam, M.S. Islam, M.A. Zubair, H.M. Usama, M.S. Azam, A. Sharif, J. Alloys Compd. 735, 2584 (2018).

[20] X.Y. Yuan, L. Shi, J.Y. Zhao, S.M. Zhou, Y. Li, C.Z. Xie, J.H. Guo, J. Alloys Compd. 708, 93 (2017)

[21] N. Kumar, A. Shukla, C. Behera, R.N.P. Choudhary, J. Alloys Compd. 688, 858 (2016)

[22] R. Palai, R.S. Katiyar, H. Schmid, P. Tissot, S.J. Clark, J. Robertson, S.A.T. Redfern, G. Catalan, J.F. Scott, Phys. Rev. B 77, 014110 (2008). 
[23] E. Wul, PowdMult: An Interactive Powder Diffraction Data Interpretation Index Program (School of Physical Science, Flinders University of South Australia, Adelaide 1989).

[24]B.D. Cullity, Elements of X-Ray Diffraction, $2^{\text {nd }}$ edn, (Addison-Wesley, Publishing Company Inc. Reading, MA, USA. 1978).

[25] K.S. Kumar, C. Venkateswaran, D. Kannan, B. Tiwari, M.S.R. Rao, J. Phys. D. Appl. Phys. 45, 415302 (2012).

[26] N. Kumar, A. Shukla, N. Kumar, R.N.P. Choudhary, Ceram. Int. 45, 822 (2019).

[27] T. Acharya, R.N.P. Choudhary, J. Electron. Mater. 44, 271 (2015).

[28] N. Kumar, A. Shukla, R.N.P. Choudhary, Prog. Nat. Sci.: Mater. Int. 28, 308-314 (2018)

[29] L. Thansanga, A. Shukla, N. Kumar, R.N.P. Choudhary J. Mater. Sci: Mater. Electron. 31 10006 (2020)

[30] N. Adhlakha, K. L. Yadav, Study of dielectric, magnetic and magnetoelectric behavior of (x)NZF-(1-x)PLSZT multiferroic composites, IEEE Trans. Dielectr. Electr. Insul. 21(5), 2055-2061 (2014)

[31] C.G. Koop, On the dispersion of resistivity and dielectric constant of some semiconductors at audio frequencies. Phys. Rev. 83, 121-124 (1951)

[32] S. Sen, R.N.P. Choudhary, Impedance studies of $\mathrm{Sr}$ modified $\mathrm{BaZr}_{0.05} \mathrm{Ti}_{0.95} \mathrm{O}_{3}$, ceramics. Mater. Chem. Phys. 87(2), 256-263 (2004)

[33] S. Brahma, R.N.P. Choudhary, A.K. Thakur, Physica B 355, 188-201 (2005)

[34] A. Belboukhari, Z. Abkhar, Y. Gagou, J. Belhadi, R. Elmoznine, D. Mezzane, M.E. Marssi, I. Luk’yanchuk, Eur. Phys. J. B 85, 215 (2012)

[35]H. Jain, C. Hsieh, J. Non-Cryst. Solids 172, 1408 (1994)

[36] S. Chatterjee, P.K. Mahapatra, R.N.P. Choudhary, A.K. Thakur, Phys. Status Solidi 201, 588 (2004)

[37] J. Rout, B.N. Parida, P.R. Das, R.N.P. Choudhary, J. Electron. Mater. 43, 732 (2014).

[38] A.K. Jonscher, Nature 267, 673 (1977)

[39] A.R. James, K. Srinivas, Mater. Res. Bull. 34, 1301 (1999)

[40] I.M. Hodge, M.D. Ingram, A.R. West, Anal. Chem. 58, 429-432 (1975)

[41] M. A. Rahman, A. K. M. Akther Hossain, Phys. Scr. 89 (11), 115811 (2014)

[42] R. Rai, I. Coondoo, R. Rani, I. Bdikin, S. Sharma, A.L. Kholkin, Curr. Appl. Phys. 13, 430 (2013)

[43] M.K. Shamim, S. Sharma, S. Sinha, E. Nasreen, J. Adv. Dielectr. 7, 1750020 (2017)

[44] S. Sasaki, C.T. Prewitt, J.D. Bass, Acta. Crystallogr. Sect. C: Cryst. Struct. Commun. 43, 1668 (1987) 
[45] Y.B. Taher, N. Moutia, A. Oueslati, M. Gargouri, RSC Adv. 6: 39750 (2016)

[46] R. Ranjan, R. Kumar, N. Kumar, B. Behera, R.N.P. Choudhary, J. Alloys. Compd. 509, $6388(2011)$

[47]F. Borsa, D.R. Torgeson, S.W. Martin, H.K. Patel, Phys. Rev. B: Condens. Matter. Mater. Phys. 46, 795 (1992)

[48] R. Schmidt, S. Pandey, P. Fiorenza, and D.C. Sinclair, RSC Adv. 3, 14580 (2013)

[49] C.K. Suman, K. Prasad, R.N.P. Choudhary, J. Mater. Sci. 41, 369 (2006)

[50] S. Sahoo, P.K. Mahapatra, R.N.P. Choudhary, M.L. Nandagoswami, A. Kumar, Mater. Res. Express 3, 065017 (2016)

[51] B. Natesan, N.K. Karan, R.S. Katiyar, Phys. Rev. E 74, 042801 (2006)

[52] P. Balaya, P.S. Goyal, J. Non-Cryst Solids 351, 1573 (2005)

[53] A.P. Barranco, Y.G. Abreu, R.L. Noda, J. Phys. Condens. Mater. 20, 505208 (2008)

[54] J.S. Lee, S. Lee, T.W. Noh, Appl. Phys. Rev. 2, 031303 (2015)

[55] B. Dhanalakshmi, P. Kollu, B. Chandra, B.P. Rao, P.S.V.S. Rao, Ceram. Int. 43, 9272$9275(2017)$ 


\section{FIGURE CAPTIONS:}

Fig. 1 The XRD pattern of sintered $\mathrm{Bi}\left(\mathrm{Fe}_{0.85} \mathrm{Dy}_{0.15}\right) \mathrm{O}_{3}$ material.

Fig. 2a Scanning electron micrograph and b EDXMA of sintered $\mathrm{Bi}\left(\mathrm{Fe}_{0.85} \mathrm{Dy}_{0.15}\right) \mathrm{O}_{3}$ material.

Fig. 3a The temperature dependent dielectric constant $\left(\varepsilon_{r}\right)$ and $\mathbf{b}$ dielectric loss $(\tan \delta)$ for sintered $\mathrm{Bi}\left(\mathrm{Fe}_{0.85} \mathrm{Dy}_{0.15}\right) \mathrm{O}_{3}$ compound.

Fig. 4a Dielectric constant versus frequency $\left(\varepsilon_{\mathrm{r}}\right)$ and $\mathbf{b}$ dielectric loss $(\tan \delta)$ as a function of frequency for sintered $\mathrm{Bi}\left(\mathrm{Fe}_{0.95} \mathrm{Dy}_{0.05}\right) \mathrm{O}_{3}$ compound.

Fig. 5a The change of real component of impedance $\left(Z^{\prime}\right)$ versus frequency $\mathbf{b}$ variation of imaginary component of impedance ( $\left.Z^{\prime \prime}\right)$ with frequency and $\mathbf{c}$ Nyquist Plot ( $Z^{\prime}$ vs $Z$ ') for sintered $\mathrm{Bi}\left(\mathrm{Fe}_{0.85} \mathrm{Dy}_{0.15}\right) \mathrm{O}_{3}$ compound.

Fig. 6a The variation of component of real modulus $\left(M^{\prime}\right)$ versus frequency and $\mathbf{b}$ characteristics of component of imaginary modulus ( $\left.M^{\prime \prime}\right)$ versus frequency for sintered $\mathrm{Bi}\left(\mathrm{Fe}_{0.85} \mathrm{Dy}_{0.15}\right) \mathrm{O}_{3}$ compound.

Fig. 7a Frequency dependent ac-conductivity and $\mathbf{b}$ temperature dependent ac-conductivity of $\mathrm{Bi}\left(\mathrm{Fe}_{0.85} \mathrm{Dy}_{0.15}\right) \mathrm{O}_{3}$ compound.

Fig. 8 Ferroelectric hysteresis loop for BFDO15 


\section{TABULATION:}

Table 1: Comparison of $d_{o b s}$ and $d_{c a l}$ values of high reflections of $\mathrm{Bi}\left(\mathrm{Fe}_{0.85} \mathrm{Dy}_{0.15}\right) \mathrm{O}_{3}$ with a relative intensity $\left(I / I_{0}\right)$ at room temperature.

Table 2 Composition of sintered BFDO15 sample determined by EDXS.

Table 3 Comparison of temperature dependent dielectric constant $\left(\varepsilon_{\mathrm{r}}\right)$ and dielectric loss $(\tan \delta)$ of sintered $\mathrm{Bi}\left(\mathrm{Fe}_{0.85} \mathrm{Dy}_{0.15}\right) \mathrm{O}_{5}$ compound at selected temperatures and frequencies.

Table 4 The activation energy $\left(\mathrm{E}_{\mathrm{a}}\right)$ of $\mathrm{Bi}\left(\mathrm{Fe}_{0.85} \mathrm{Dy}_{0.15}\right) \mathrm{O}_{3}$ material calculated from the slope using Arrhenius relation at different temperature regions. 
Table:

Table 1: Comparison of $d_{o b s}$ and $d_{c a l}$ values of high reflections of $\mathrm{Bi}\left(\mathrm{Fe}_{0.85} \mathrm{Dy}_{0.15}\right) \mathrm{O}_{3}$ with a relative intensity $\left(I / I_{0}\right)$ at room temperature.

\begin{tabular}{|c|c|c|c|c|c|c|c|}
\hline $2 \theta$ & $d_{o b s}(\AA)$ & $d_{c a l}(\AA)$ & $I / I_{o}$ & $h$ & $k$ & $l$ & $\begin{array}{l}\text { Crystallite } \\
\text { size }(\mathrm{nm})\end{array}$ \\
\hline 22.84 & 3.8902 & 3.8877 & 60 & 1 & 1 & 0 & 47 \\
\hline 24.84 & 3.5813 & 3.5793 & 20 & 0 & 1 & 8 & 55 \\
\hline 25.58 & 3.4794 & 3.4763 & 21 & 1 & 2 & 2 & 55 \\
\hline 27.8 & 3.2063 & 3.1988 & 56 & 1 & 3 & 0 & 51 \\
\hline 30.5 & 2.9284 & 2.929 & 19 & 1 & 3 & 4 & 50 \\
\hline 31.88 & 2.8047 & 2.805 & 30 & 1 & 4 & 1 & 10 \\
\hline 32.5 & 2.7526 & 2.7558 & 100 & 0 & 2 & 10 & 51 \\
\hline 33.02 & 2.7104 & 2.7092 & 48 & 1 & 0 & 8 & 43 \\
\hline 33.94 & 2.639 & 2.6402 & 15 & 0 & 6 & 0 & 48 \\
\hline 39.64 & 2.2717 & 2.2712 & 18 & 1 & 2 & 10 & 29 \\
\hline 40.56 & 2.2223 & 2.2221 & 15 & 0 & 3 & 12 & 36 \\
\hline 41.72 & 2.1631 & 2.1628 & 13 & 1 & 3 & 10 & 34 \\
\hline 46.54 & 1.9497 & 1.9495 & 26 & 2 & 1 & 3 & 31 \\
\hline 48.06 & 1.8915 & 1.8908 & 11 & 1 & 6 & 8 & 37 \\
\hline 52.48 & 1.7421 & 1.7431 & 22 & 0 & 8 & 8 & 34 \\
\hline 52.96 & 1.7257 & 1.7269 & 16 & 0 & 7 & 11 & 51 \\
\hline 55.76 & 1.6472 & 1.6475 & 12 & 2 & 1 & 10 & 34 \\
\hline 57.06 & 1.6127 & 1.6117 & 14 & 1 & 9 & 0 & 37 \\
\hline 58.64 & 1.573 & 1.5736 & 16 & 0 & 6 & 15 & 38 \\
\hline 61.86 & 1.4986 & 1.4988 & 10 & 2 & 7 & 1 & 29 \\
\hline 63.48 & 1.4642 & 1.4645 & 9 & 2 & 6 & 8 & 25 \\
\hline 67.9 & 1.3792 & 1.38 & 11 & 1 & 0 & 20 & 19 \\
\hline 77.36 & 1.2325 & 1.2326 & 11 & 0 & 7 & 20 & 23 \\
\hline
\end{tabular}

Phase : Orthorhombic symmetry 
Table 2 Composition of sintered $\mathrm{Bi}\left(\mathrm{Fe}_{0.85} \mathrm{Dy}_{0.15}\right) \mathrm{O}_{3}$ sample determined by EDXS.

\begin{tabular}{lll}
\hline Element & Weight\% & Atomic\% \\
\hline $\mathrm{Bi}$ & 67.74 & 24.59 \\
$\mathrm{Fe}$ & 17.06 & 23.17 \\
$\mathrm{O}$ & 10.56 & 50.05 \\
$\mathrm{Dy}$ & 04.64 & 02.17 \\
\hline
\end{tabular}

Table 3 Comparison of temperature dependent dielectric constant $\left(\varepsilon_{\mathrm{r}}\right)$ and dielectric loss $(\tan \delta)$ of sintered $\mathrm{Bi}\left(\mathrm{Fe}_{0.85} \mathrm{Dy}_{0.15}\right) \mathrm{O}_{5}$ compound at selected temperatures and frequencies.

\begin{tabular}{lllllll}
\hline \multirow{2}{*}{ S1. No. } & \multirow{2}{*}{ Frequency } & \multicolumn{2}{c}{ Temperature $25^{\circ} \mathrm{C}$} & & \multicolumn{2}{c}{ Temperature $350^{\circ} \mathrm{C}$} \\
\cline { 3 - 4 } \cline { 6 - 7 } & & $\varepsilon_{\mathrm{r}}$ & $\tan \delta$ & & $\varepsilon_{\mathrm{r}}$ & $\tan \delta$ \\
\hline 1 & $1 \mathrm{kHz}$ & 4133 & 0.5922 & & 41410 & 14.895 \\
2 & $25 \mathrm{kHz}$ & 2000 & 0.3598 & & 14247 & 3.0906 \\
3 & $50 \mathrm{kHz}$ & 1748 & 0.3548 & & 11149 & 2.8434 \\
4 & $100 \mathrm{kHz}$ & 1512 & 0.3755 & & 6791 & 3.6484 \\
5 & $300 \mathrm{kHz}$ & 1128 & 0.4589 & & 2796 & 4.1749 \\
6 & $500 \mathrm{kHz}$ & 963 & 0.5049 & & 3032 & 1.6329 \\
7 & $1 \mathrm{MHz}$ & 751 & 0.5606 & & 1536 & 2.4861 \\
\hline
\end{tabular}

Table 4 The activation energy $\left(\mathrm{E}_{\mathrm{a}}\right)$ of $\mathrm{Bi}\left(\mathrm{Fe}_{0.85} \mathrm{Dy}_{0.15}\right) \mathrm{O}_{3}$ material calculated from the slope using Arrhenius relation at different temperature regions.

\begin{tabular}{lll}
\hline \multirow{2}{*}{ Frequency } & \multicolumn{2}{l}{ Temperature 1000/T } \\
\cline { 2 - 3 } & Region - I & Region - II \\
\hline $1 \mathrm{kHz}$ & 0.24 & 3.29 \\
$25 \mathrm{kHz}$ & 0.07 & 2.81 \\
$50 \mathrm{kHz}$ & 0.13 & 2.67 \\
$100 \mathrm{kHz}$ & 0.19 & 2.55 \\
$300 \mathrm{kHz}$ & 0.20 & 2.43 \\
$500 \mathrm{kHz}$ & 0.19 & 2.40 \\
$1 \mathrm{MHz}$ & 0.18 & 2.38 \\
\hline
\end{tabular}


Figures:

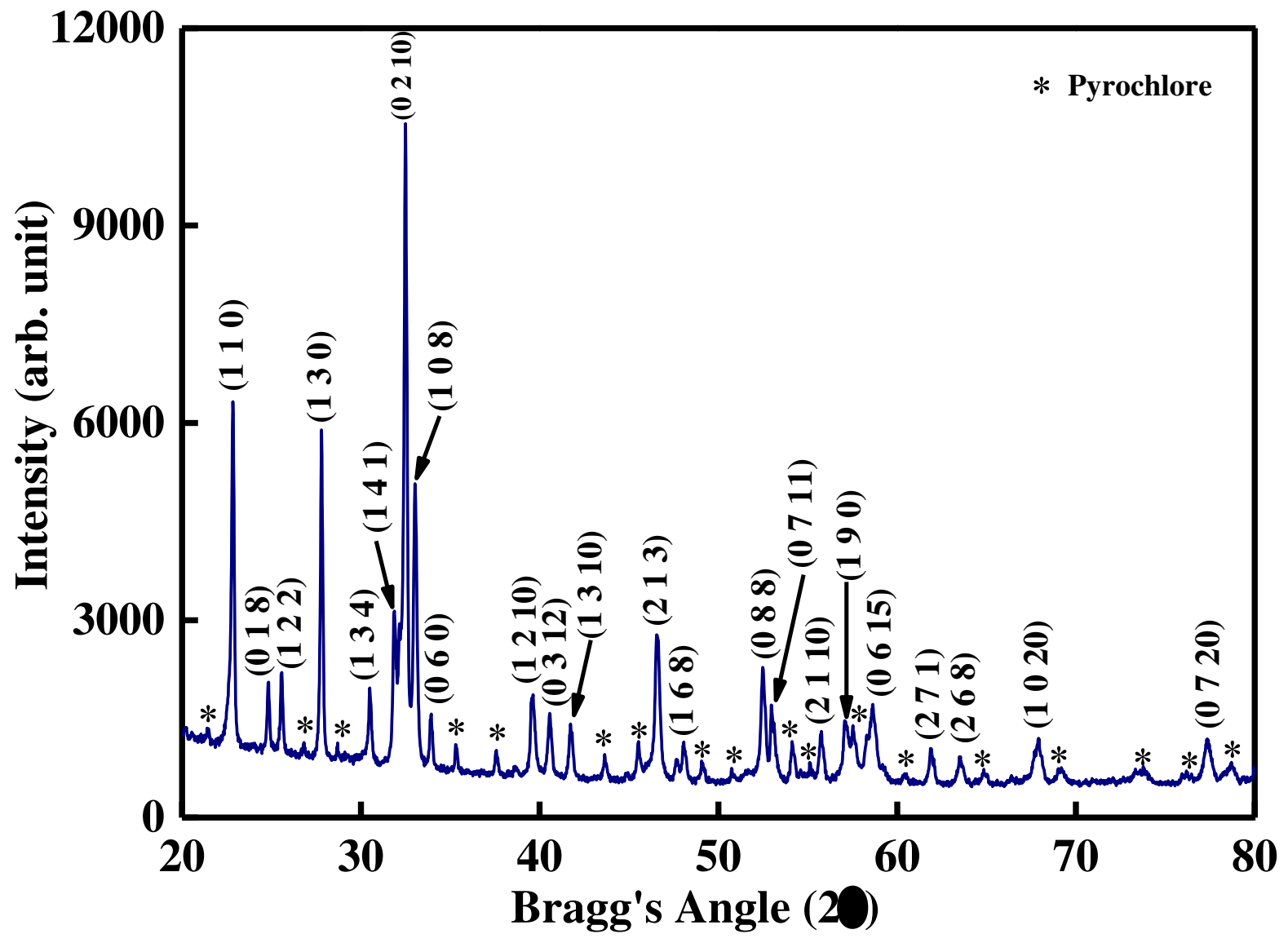

Fig. 1 The XRD pattern of sintered $\mathrm{Bi}\left(\mathrm{Fe}_{0.85} \mathrm{Dy}_{0.15}\right) \mathrm{O}_{3}$ material. 

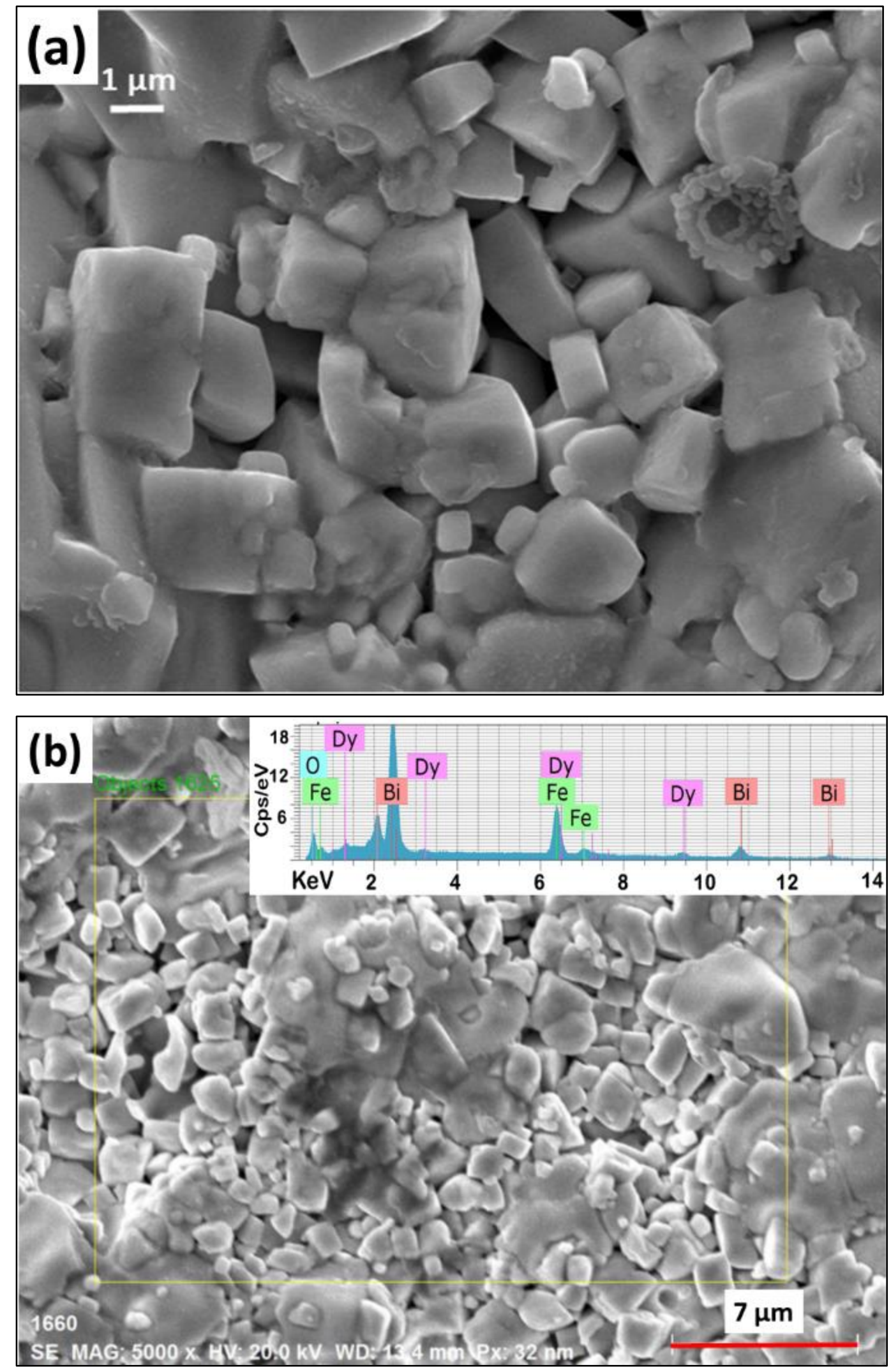

Fig. 2a Scanning electron micrograph and b EDXMA of sintered $\mathrm{Bi}\left(\mathrm{Fe}_{0.85} \mathrm{Dy}_{0.15}\right) \mathrm{O}_{3}$ material. 

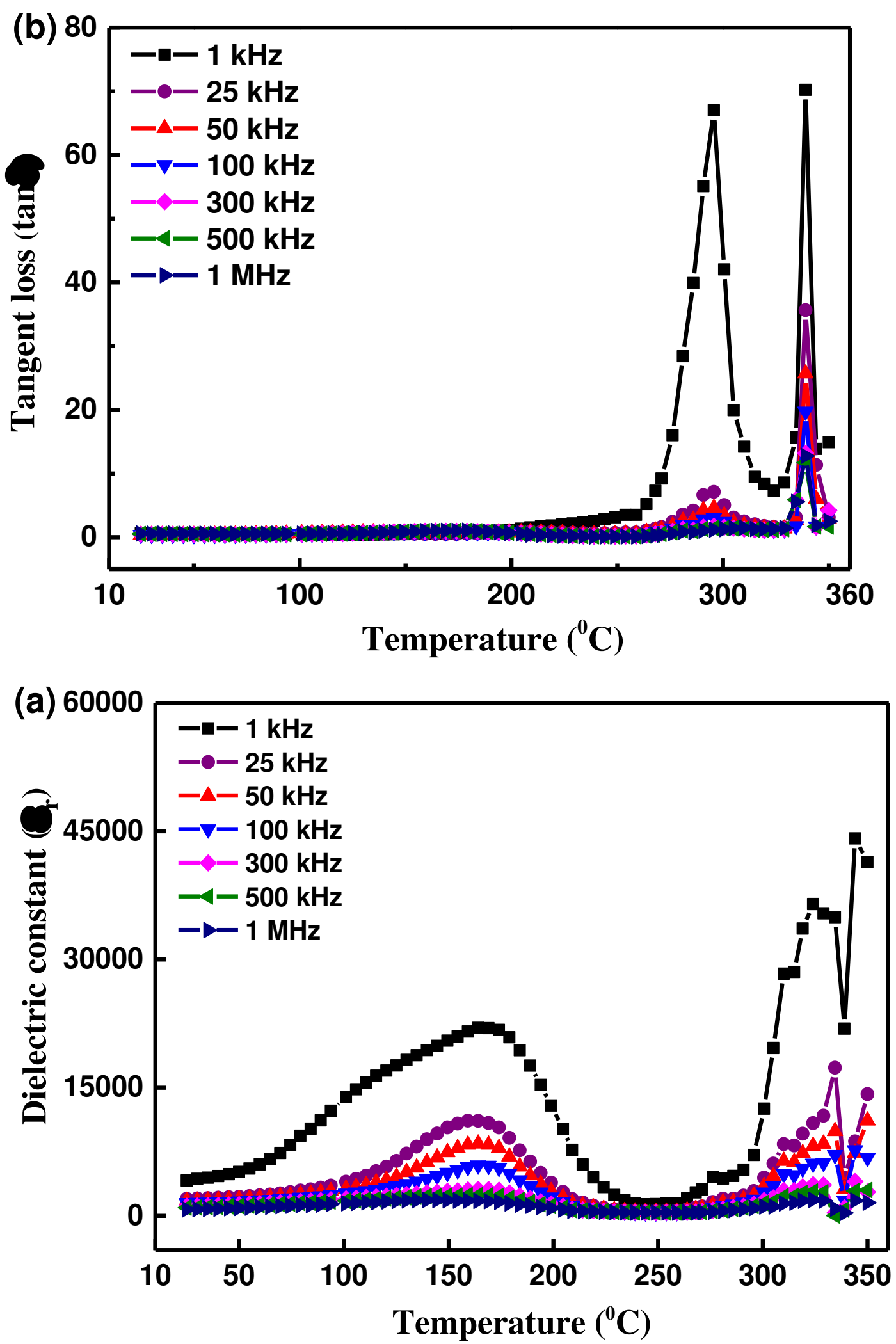

Fig. 3a The temperature dependent dielectric constant $\left(\varepsilon_{r}\right)$ and $\mathbf{b}$ dielectric loss $(\tan \delta)$ for sintered $\mathrm{Bi}\left(\mathrm{Fe}_{0.85} \mathrm{Dy}_{0.15}\right) \mathrm{O}_{3}$ compound. 

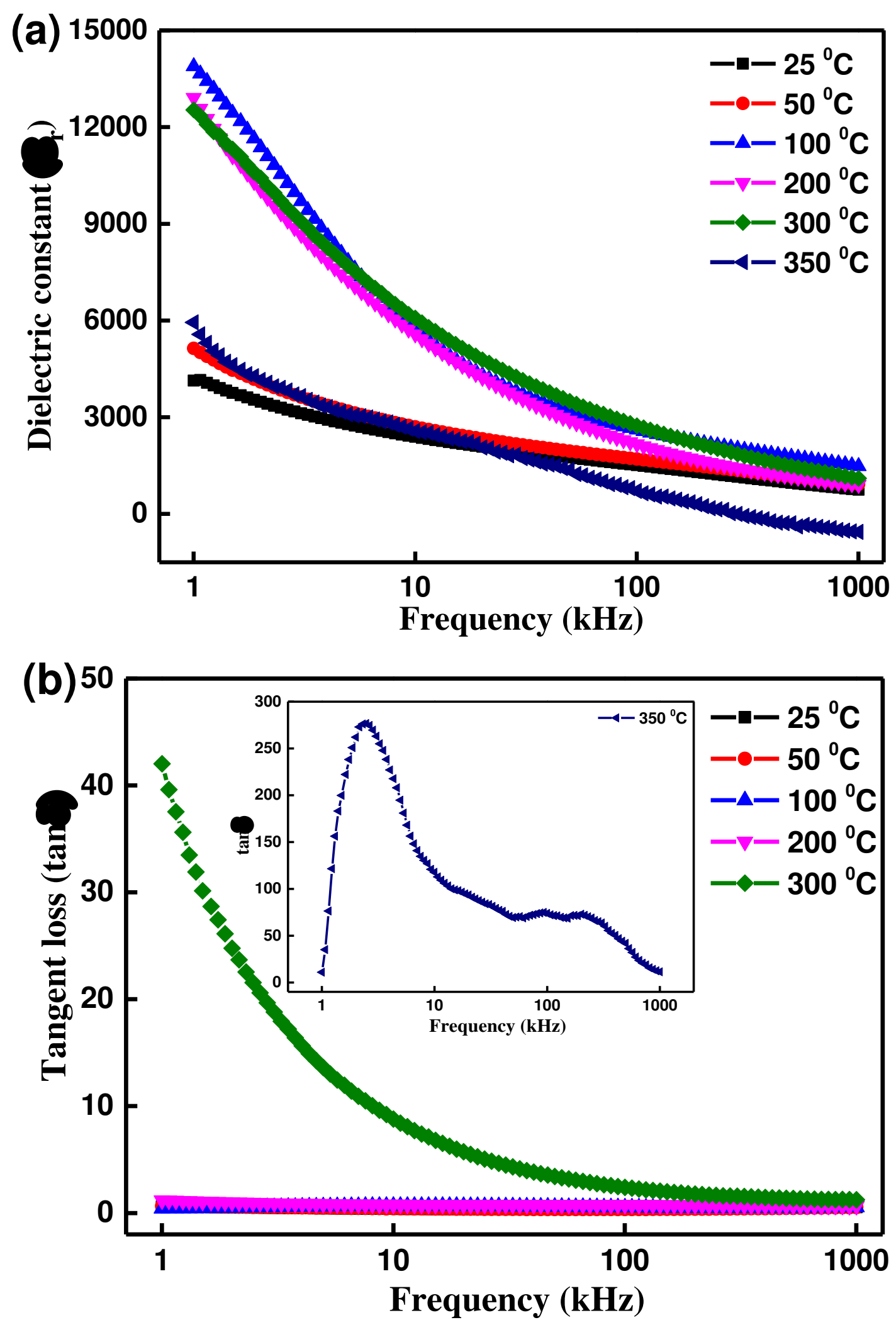

Fig. 4a Dielectric constant versus frequency $\left(\varepsilon_{\mathrm{r}}\right)$ and $\mathbf{b}$ dielectric loss $(\tan \delta)$ as a function of frequency for sintered $\mathrm{Bi}\left(\mathrm{Fe}_{0.95} \mathrm{Dy}_{0.05}\right) \mathrm{O}_{3}$ compound. 

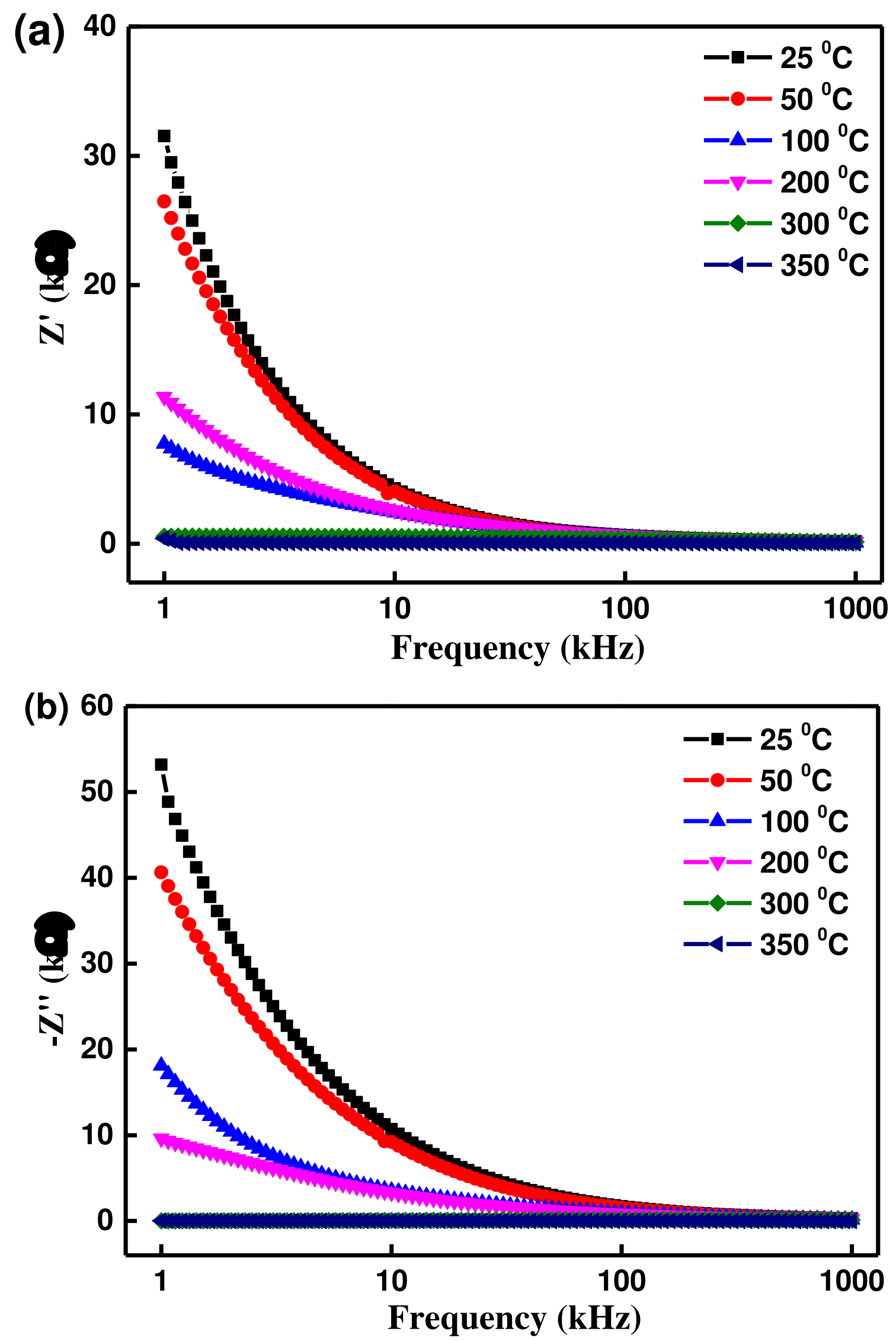


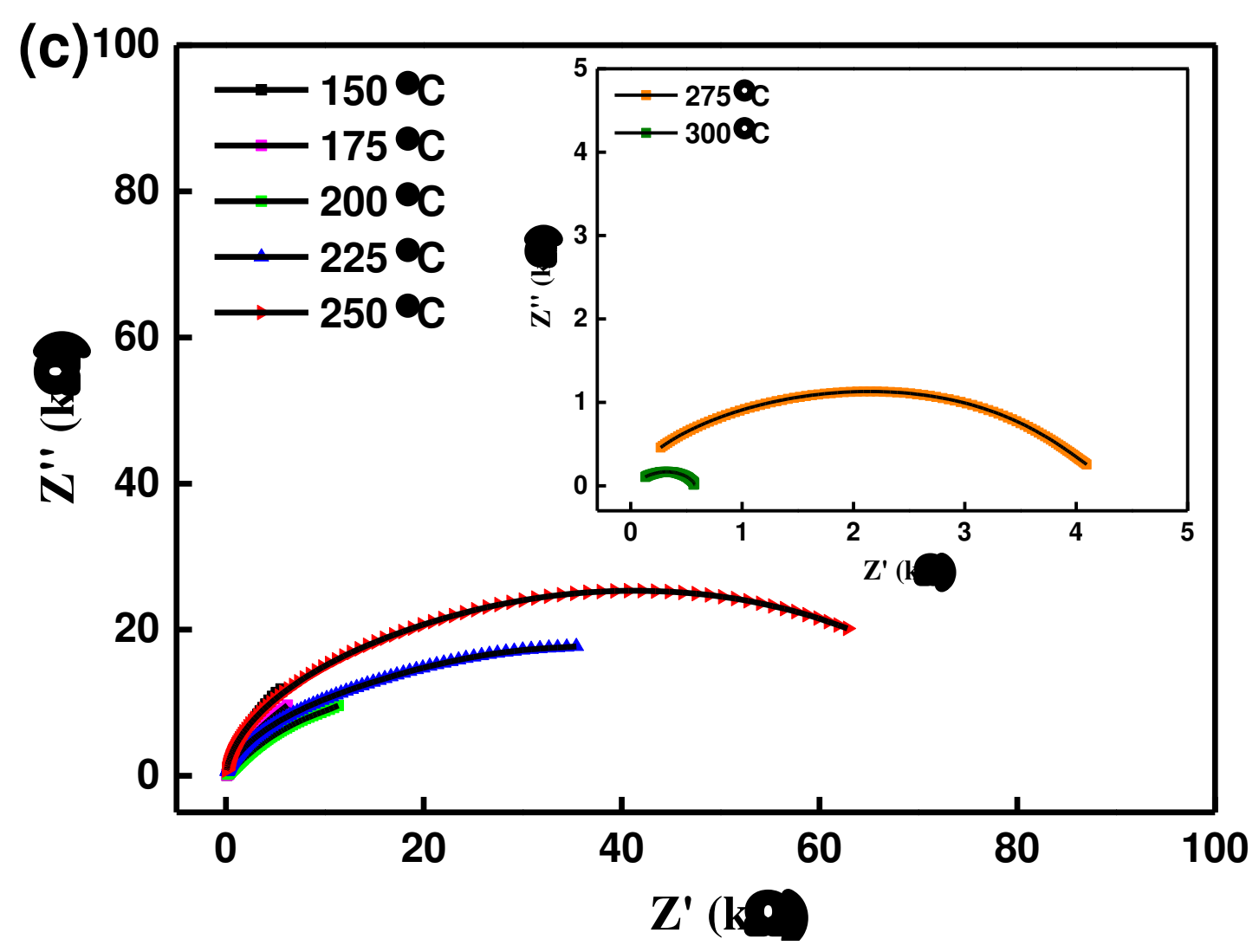

Fig. 5a The change of real component of impedance $\left(Z^{\prime}\right)$ versus frequency $\mathbf{b}$ variation of imaginary component of impedance ( $\left.Z^{\prime \prime}\right)$ with frequency and c Nyquist Plot ( $Z^{\prime}$ vs $Z$ '’) for sintered $\mathrm{Bi}\left(\mathrm{Fe}_{0.85} \mathrm{Dy}_{0.15}\right) \mathrm{O}_{3}$ compound. 

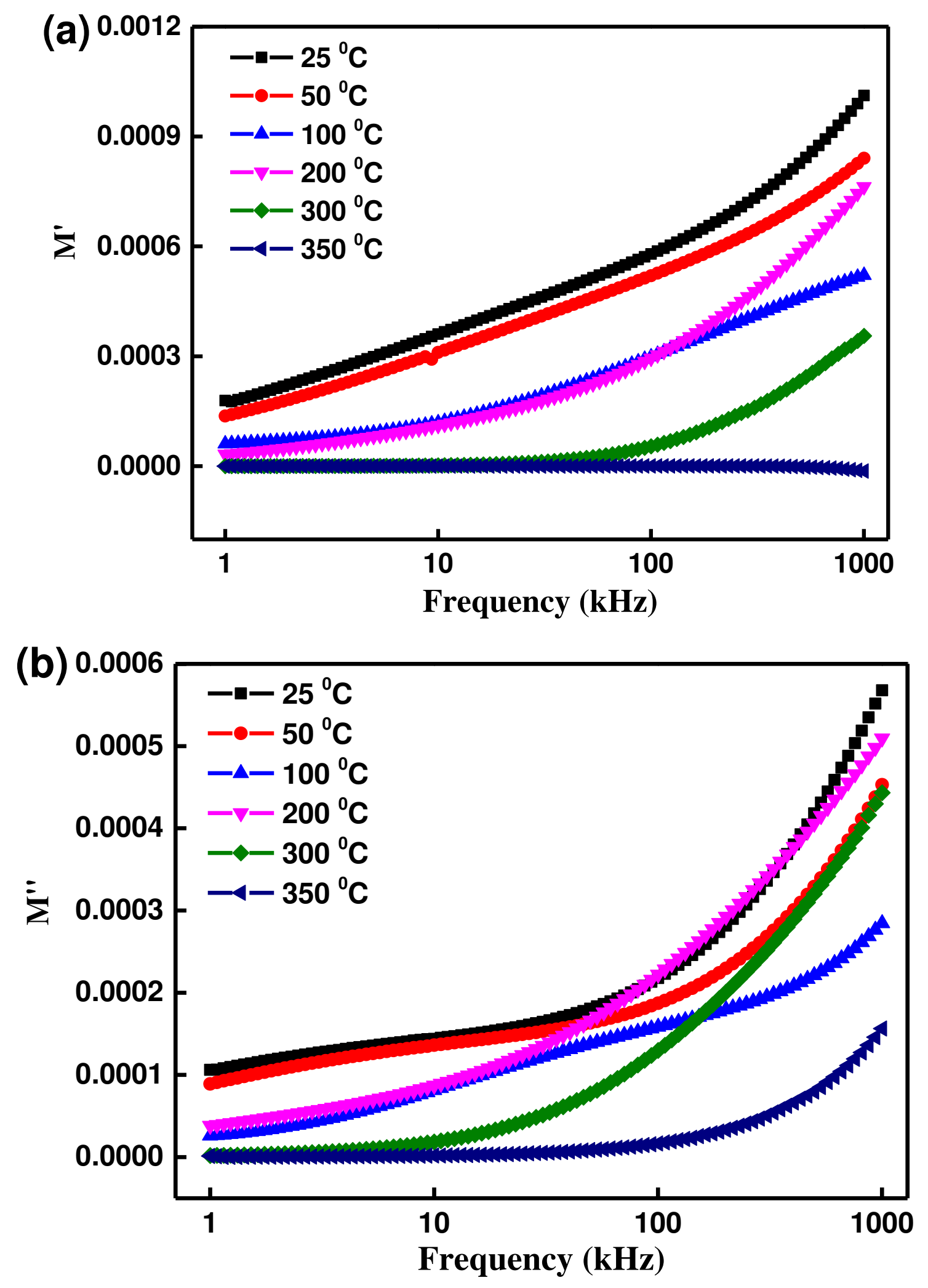

Fig. 6a The variation of component of real modulus $\left(M^{\prime}\right)$ versus frequency and $\mathbf{b}$ characteristics of component of imaginary modulus $\left(M^{\prime \prime}\right)$ versus frequency for sintered $\mathrm{Bi}\left(\mathrm{Fe}_{0.85} \mathrm{Dy}_{0.15}\right) \mathrm{O}_{3}$ compound. 

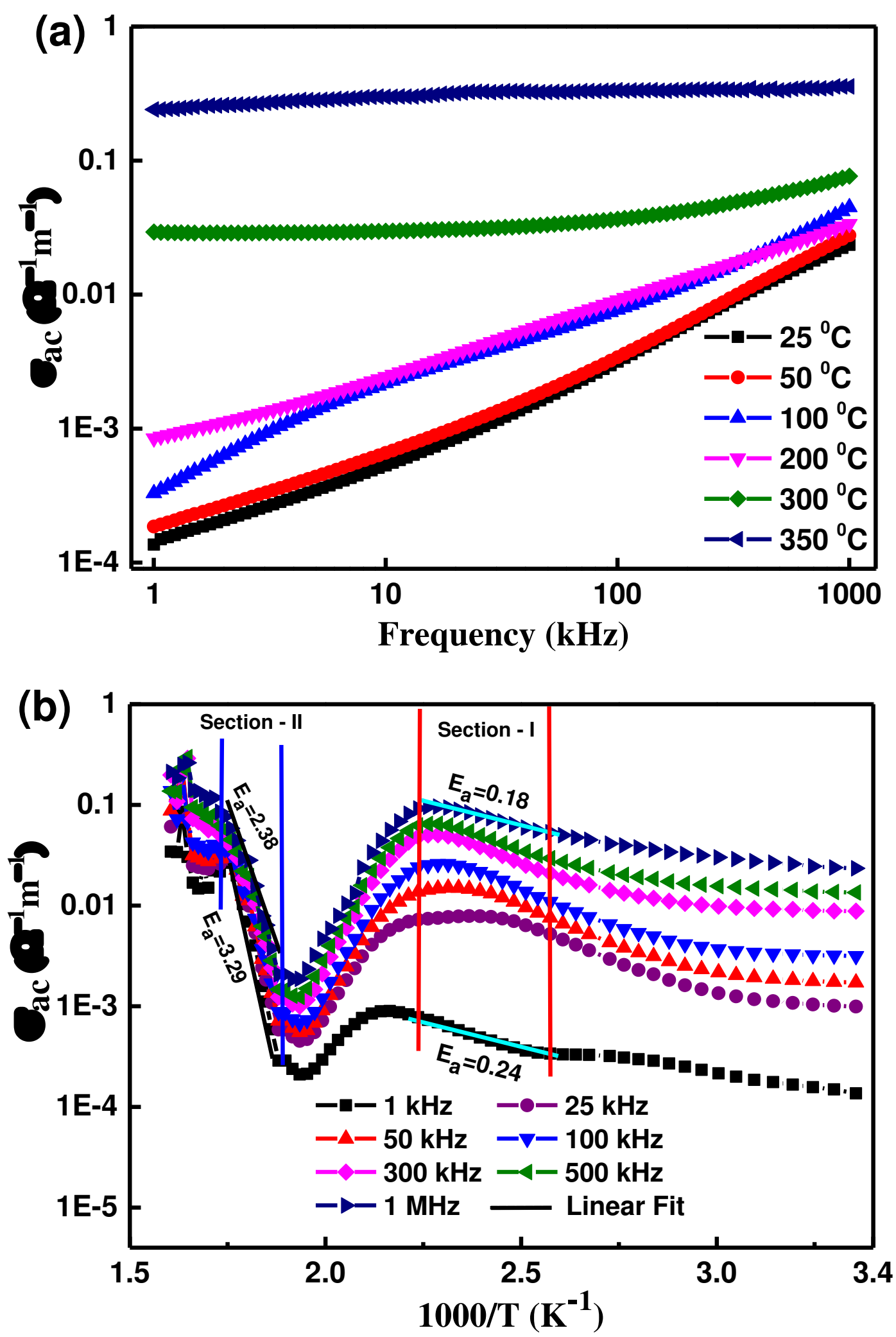

Fig. 7a Frequency dependent ac-conductivity and $\mathbf{b}$ temperature dependent ac-conductivity of $\mathrm{Bi}\left(\mathrm{Fe}_{0.85} \mathrm{Dy}_{0.15}\right) \mathrm{O}_{3}$ compound. 


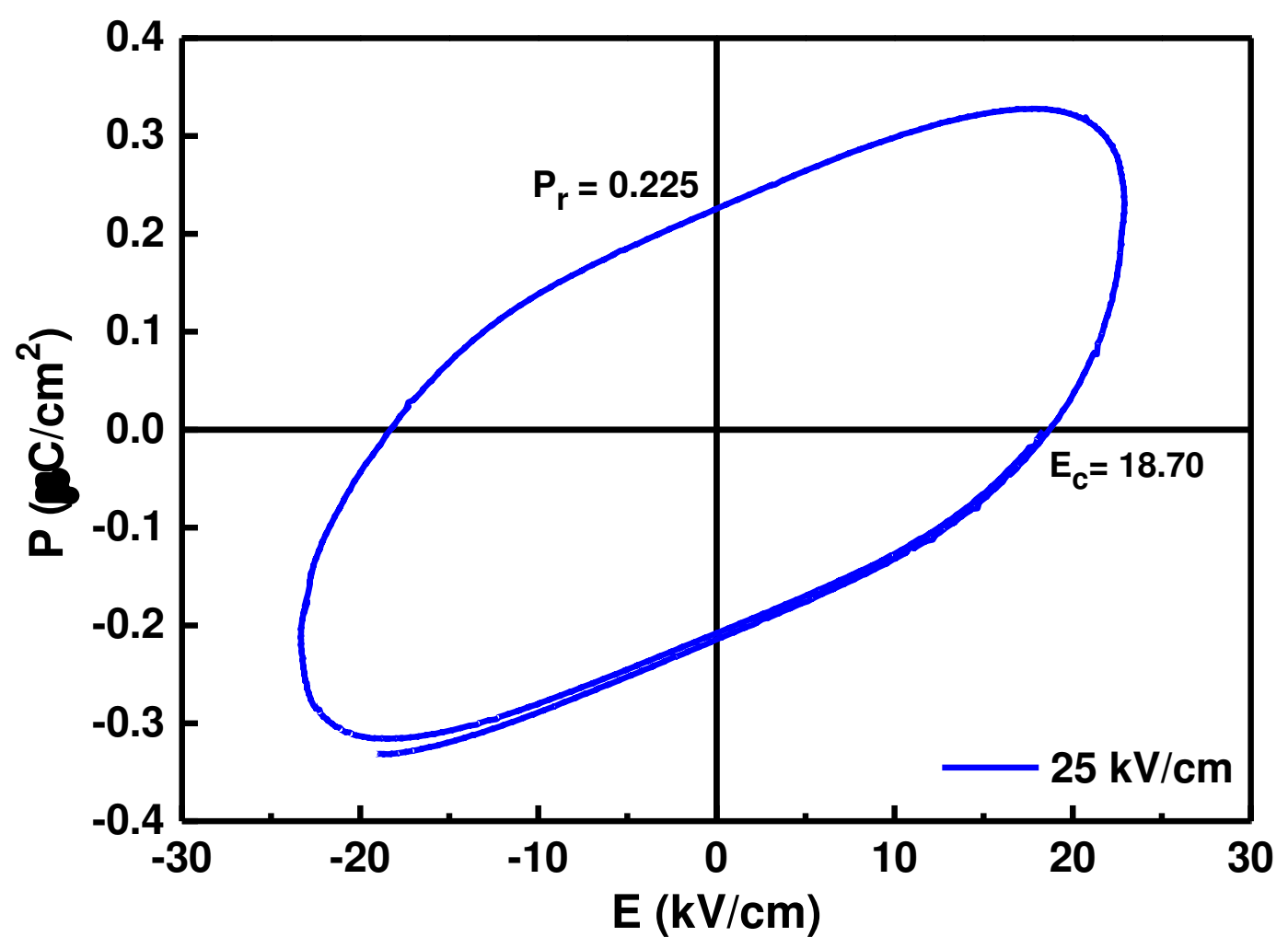

Fig. 8 Room temperature ferroelectric hysteresis $(P-E)$ loop of $\mathrm{Bi}\left(\mathrm{Fe}_{0.85} \mathrm{Dy}_{0.15}\right) \mathrm{O}_{3}$. 
Figures

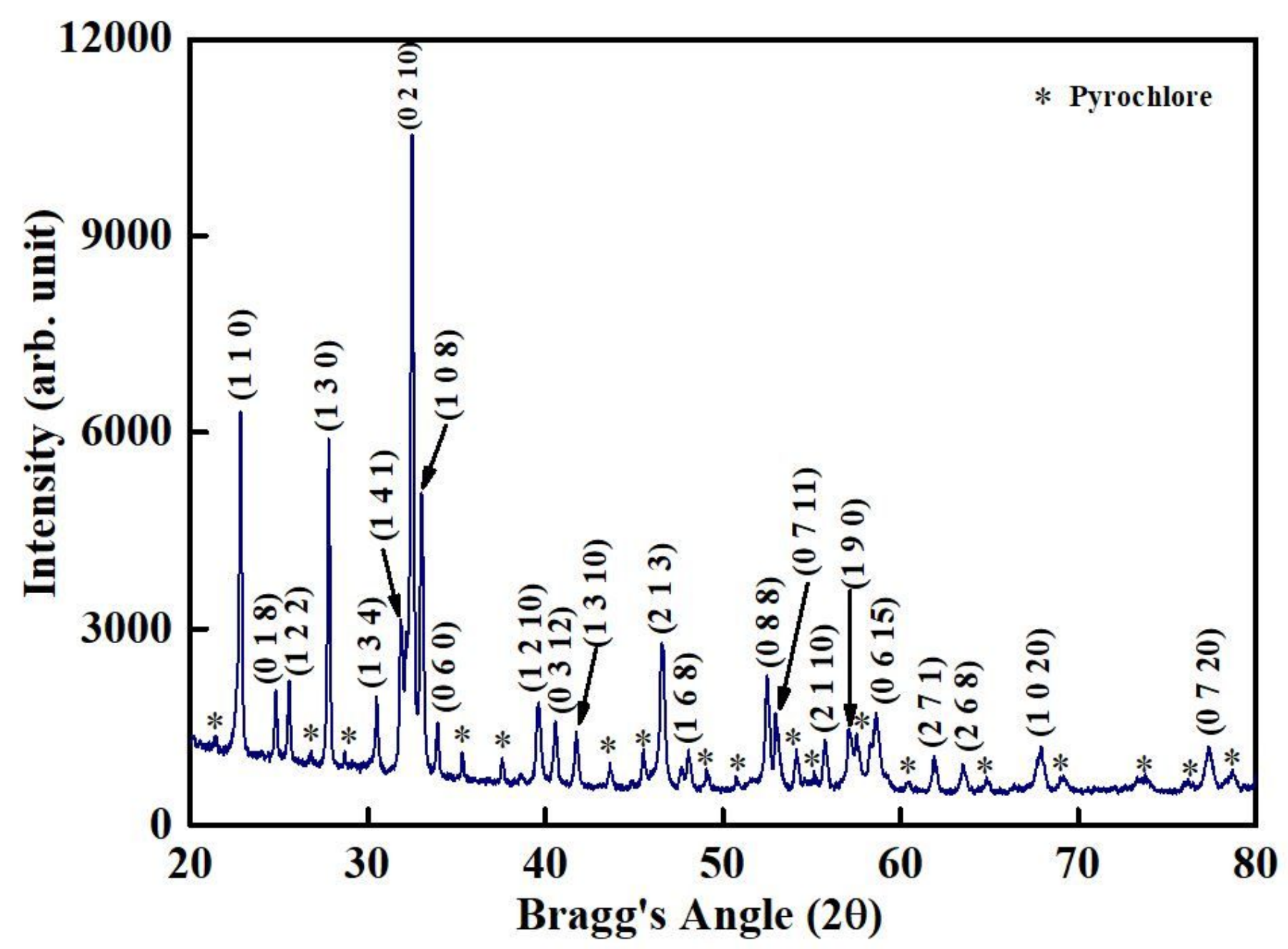

Figure 1

The XRD pattern of sintered $\mathrm{Bi}(\mathrm{Fe} 0.85 \mathrm{Dy} 0.15) 03$ material. 

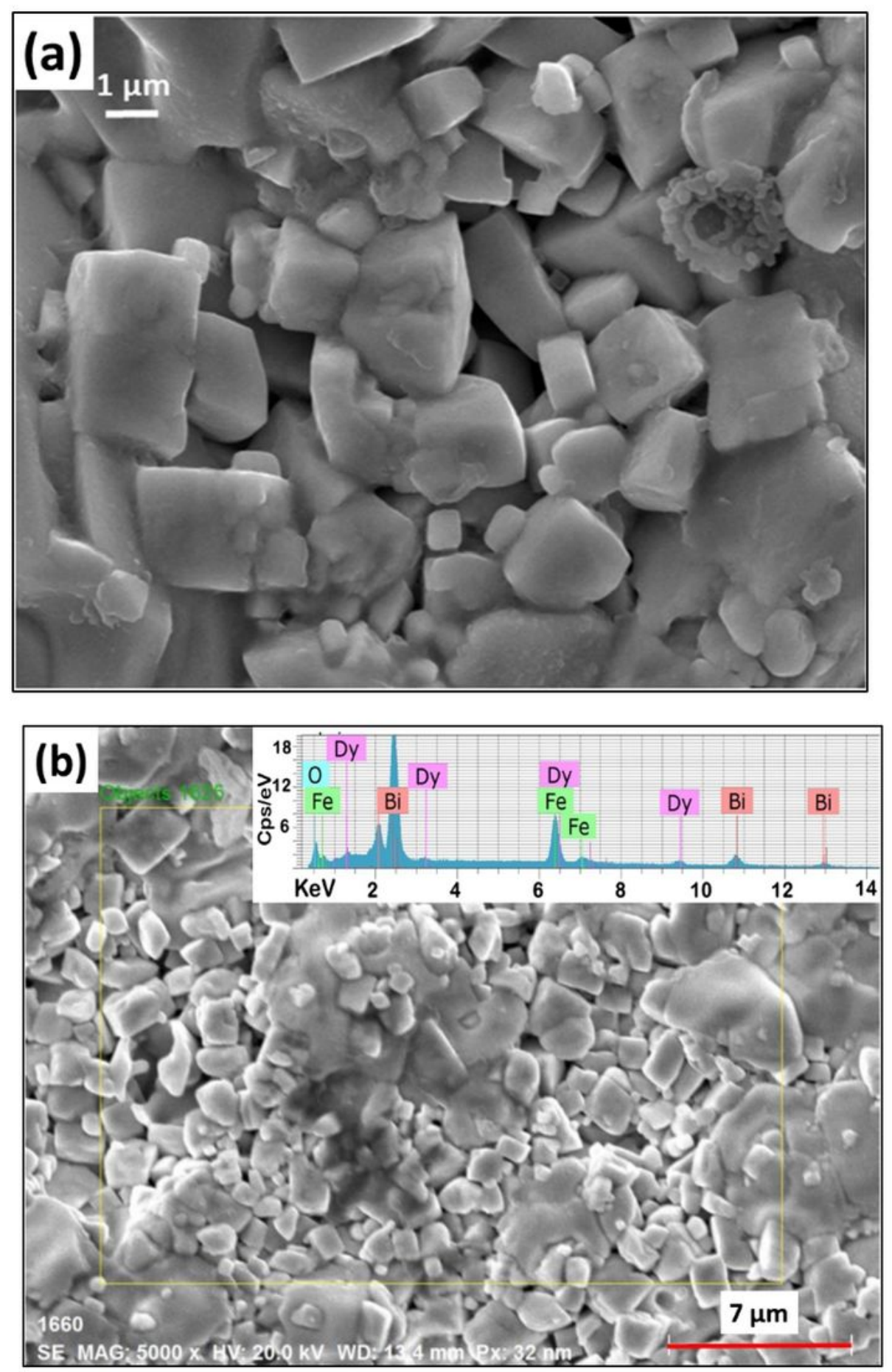

Figure 2

a Scanning electron micrograph and b EDXMA of sintered Bi(Fe0.85Dy0.15)03 material. 

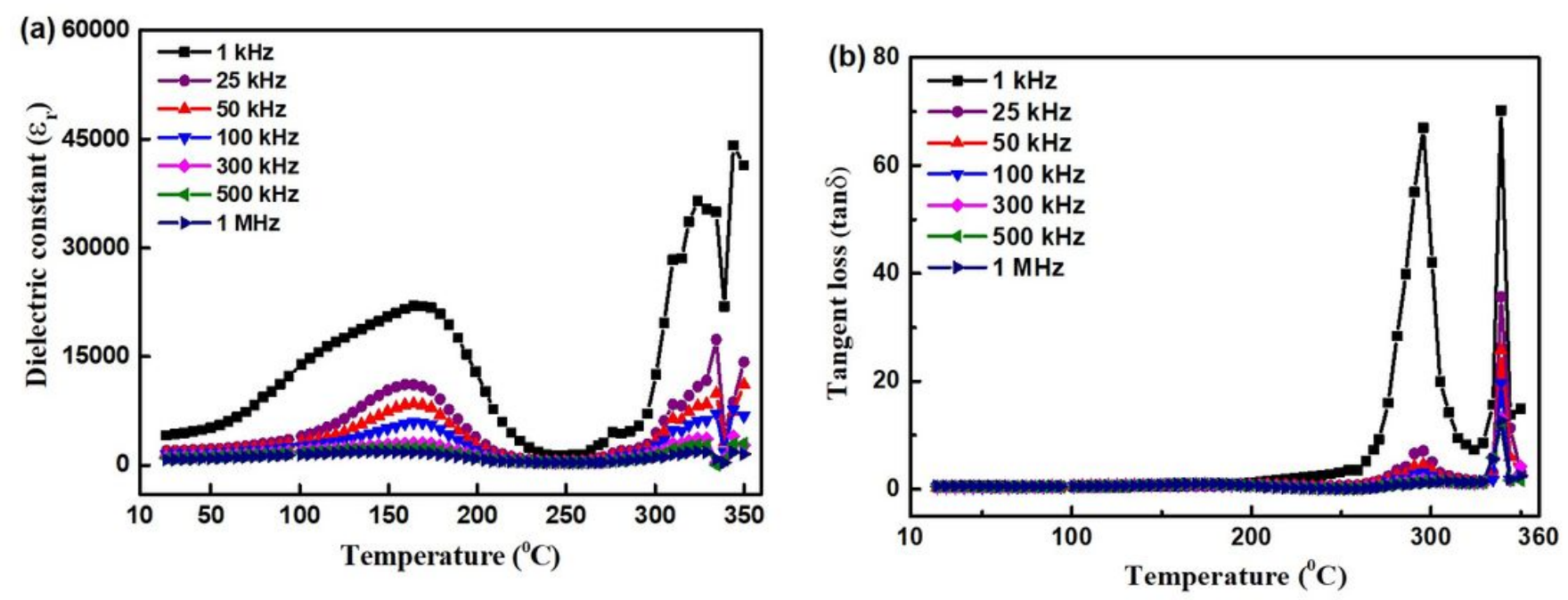

Figure 3

a The temperature dependent dielectric constant $(\nabla r)$ and $b$ dielectric loss (tan $\delta)$ for sintered $\mathrm{Bi}(\mathrm{Fe} 0.85 \mathrm{Dy} 0.15) 03$ compound.
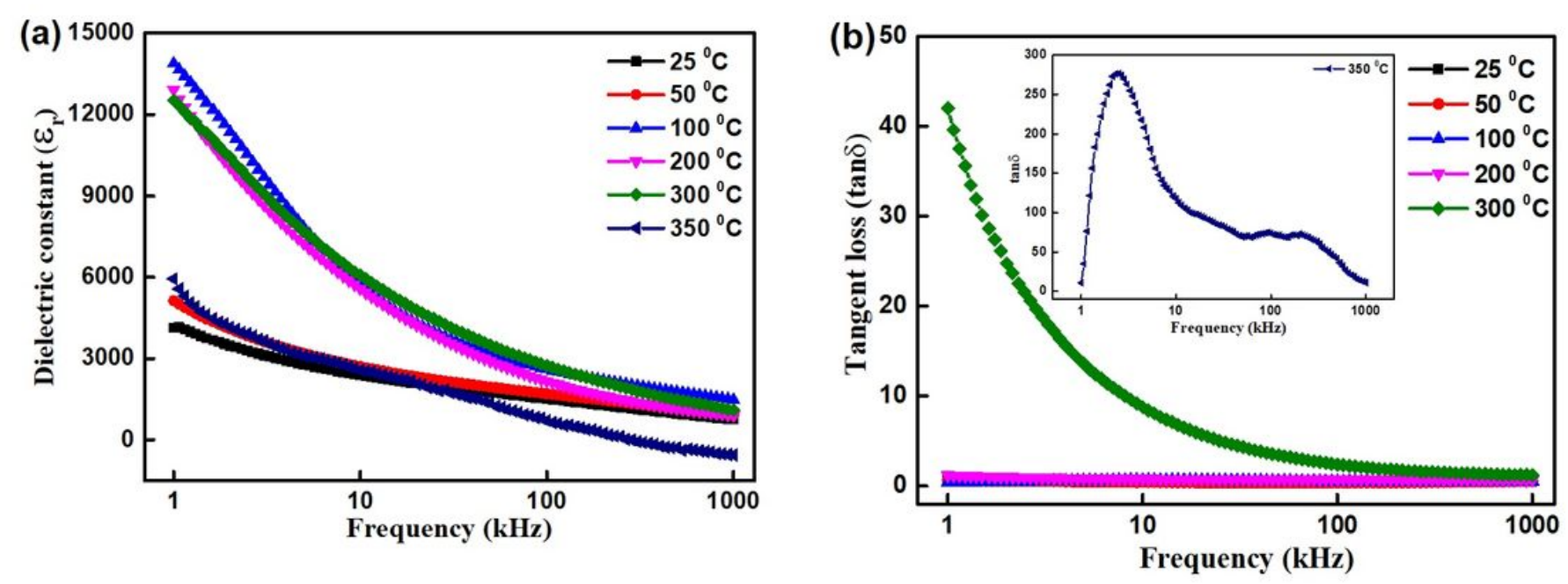

\section{Figure 4}

a Dielectric constant versus frequency ( $\nabla r$ ) and $b$ dielectric loss $(\tan \delta)$ as a function of frequency for sintered Bi(Fe0.95Dy0.05)03 compound. 

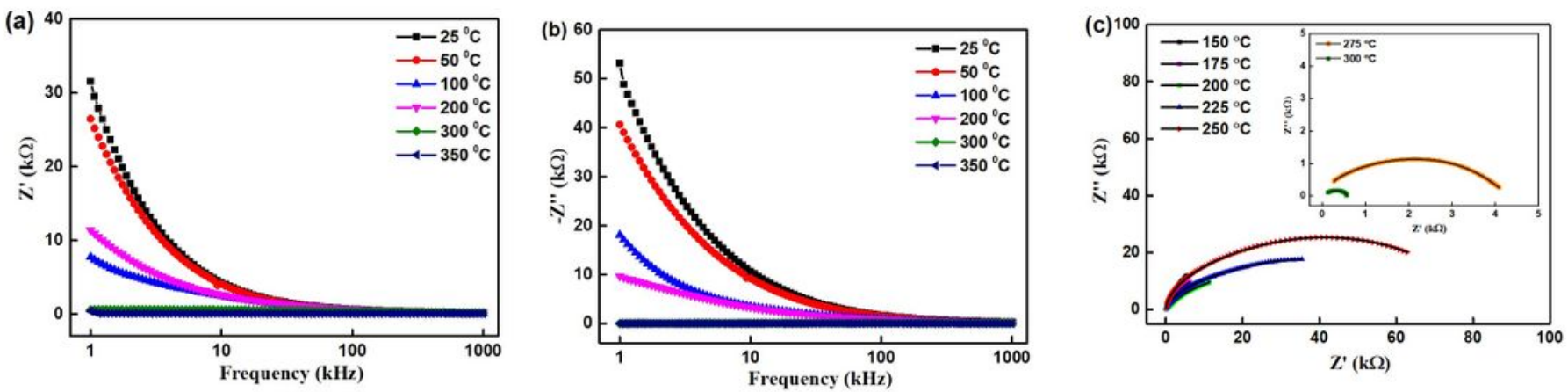

Figure 5

a The change of real component of impedance $\left(Z^{\prime}\right)$ versus frequency b variation of imaginary component of impedance (Z") with frequency and c Nyquist Plot (Z' vs Z") for sintered Bi(Fe0.85Dy0.15)03 compound. 

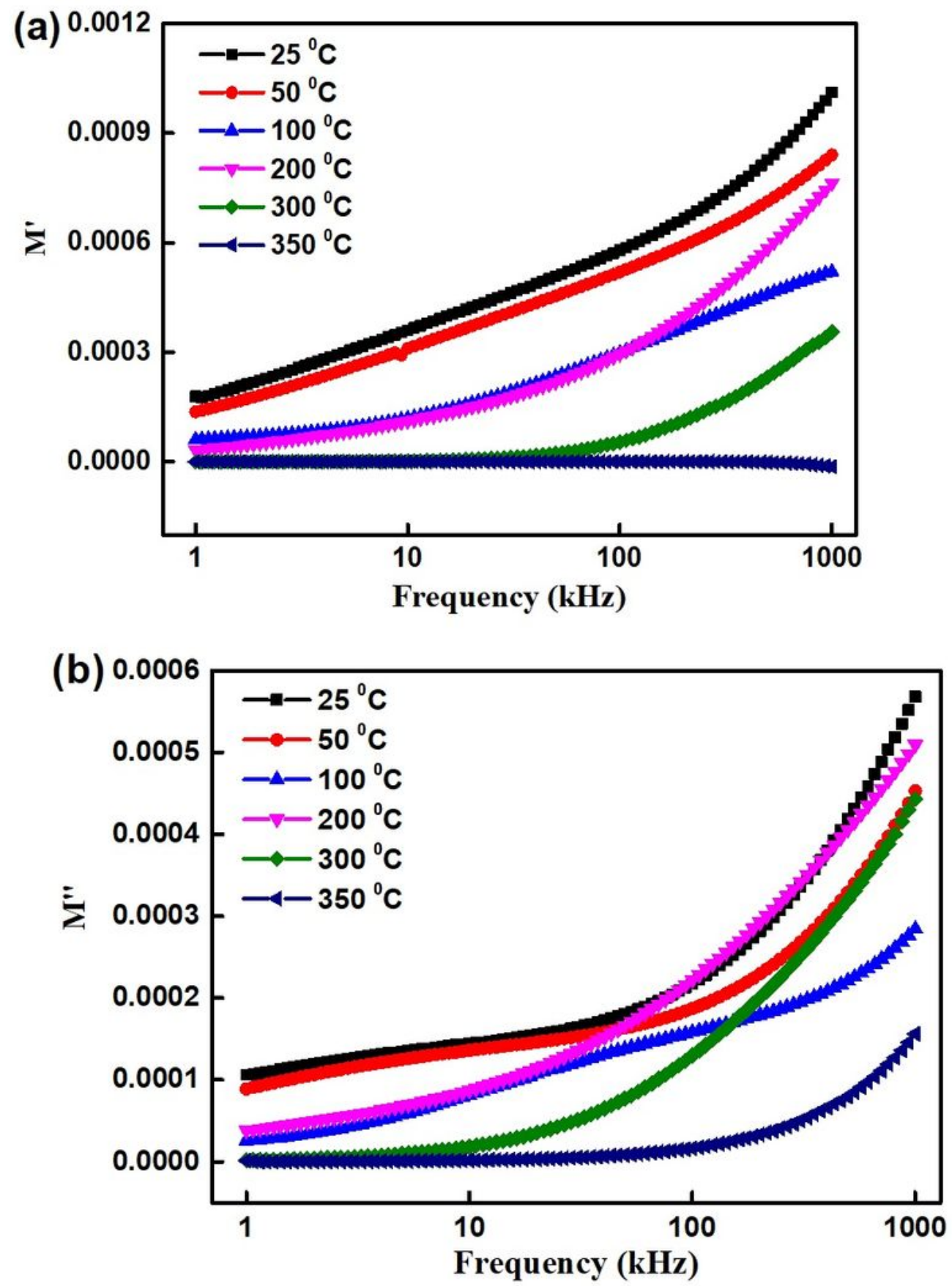

Figure 6

a The variation of component of real modulus $\left(M^{\prime}\right)$ versus frequency and b characteristics of component of imaginary modulus $\left(\mathrm{M}^{\prime \prime}\right)$ versus frequency for sintered $\mathrm{Bi}(\mathrm{Fe} 0.85 \mathrm{Dy} 0.15) 03$ compound. 

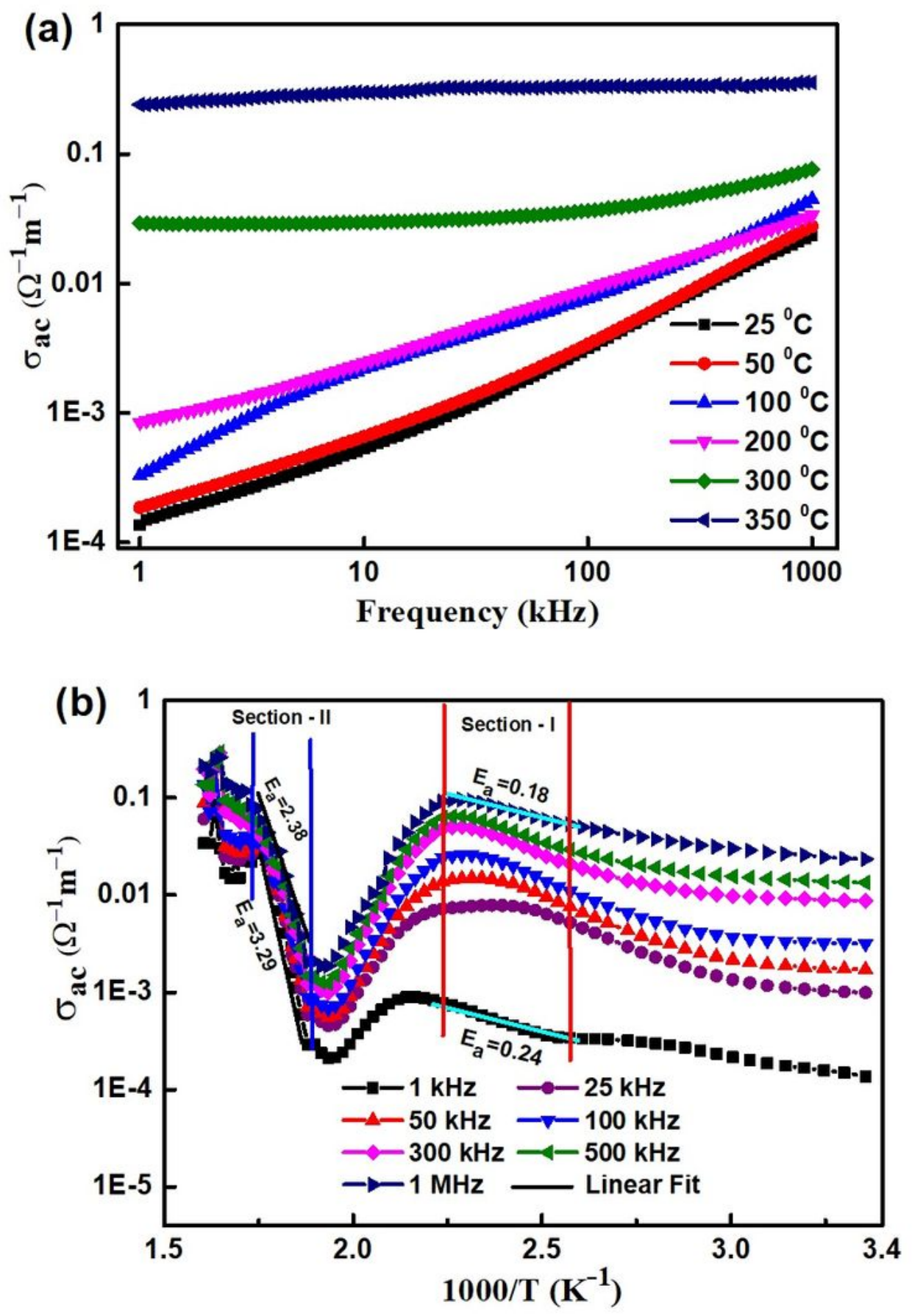

Figure 7

a Frequency dependent ac-conductivity and b temperature dependent ac-conductivity of $\mathrm{Bi}(\mathrm{Fe} 0.85 \mathrm{Dy} 0.15) 03$ compound. 


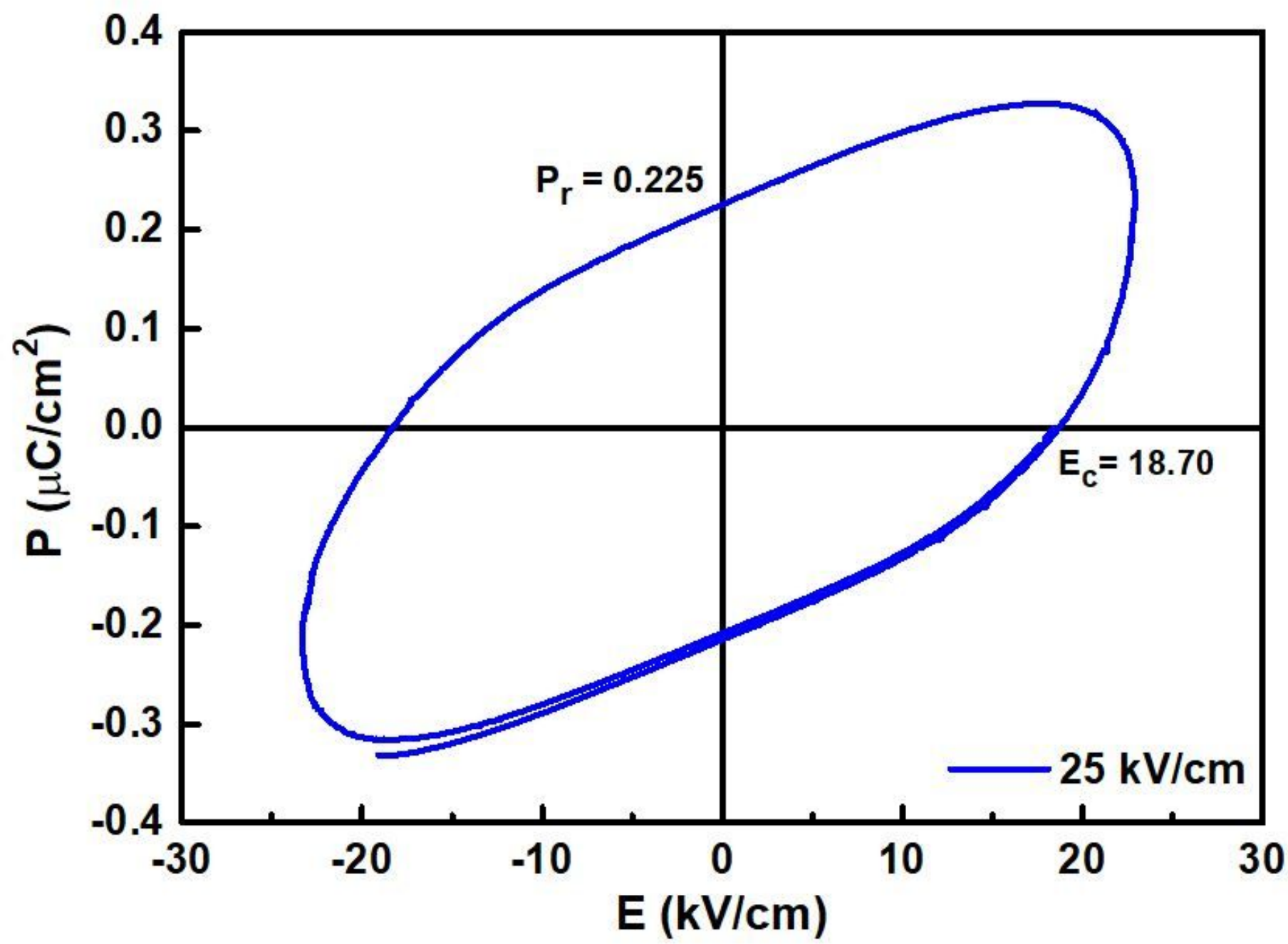

Figure 8

Room temperature ferroelectric hysteresis (P-E) loop of Bi(Fe0.85Dy0.15)03. 